Research Article

\title{
Equivalent Viscous Damping Ratio Model for Flexure Critical Reinforced Concrete Columns
}

\author{
Qin Zhang $\mathbb{D}^{1},{ }^{1}$ Zong-yan Wei, ${ }^{1}$ Jin-xin Gong, ${ }^{2}$ Ping Yu, ${ }^{2}$ and Yan-qing Zhang ${ }^{2}$ \\ ${ }^{1}$ College of Civil and Transportation Engineering, Hohai University, Nanjing, Jiangsu 210098, China \\ ${ }^{2}$ Department of Civil Engineering, Dalian University of Technology, Dalian, Liaoning 116024, China \\ Correspondence should be addressed to Qin Zhang; qinzhang8190@gmail.com
}

Received 17 November 2017; Revised 13 May 2018; Accepted 5 June 2018; Published 15 July 2018

Academic Editor: Flavio Stochino

Copyright (c) 2018 Qin Zhang et al. This is an open access article distributed under the Creative Commons Attribution License, which permits unrestricted use, distribution, and reproduction in any medium, provided the original work is properly cited.

In order to determine the energy dissipation capacity of flexure critical reinforced concrete (RC) columns reasonably, an expression for describing the hysteretic behavior including loading and unloading characteristics of flexure critical RC columns is presented, and then, a new equivalent viscous damping (EVD) ratio model including its simplified format, which is interpreted as a function of a displacement ductility factor and a ratio of secant stiffness to yield stiffness of columns, is developed based on the proposed hysteretic loop expression and experimental data from the PEER column database. To illustrate the application of the proposed equivalent damping ratio model, a case study of pushover analysis on a flexure critical RC bridge with a single-column pier is provided. The analytical results are also compared with the results obtained by other models, which indicate that the proposed model is more general and rational in predicting energy dissipation capacity of flexure critical RC structures subjected to earthquake excitations.

\section{Introduction}

Earthquake reconnaissance indicates that the structural damage of buildings and bridges is more related to relative inelastic displacements than to forces [1,2]. To better control the inelastic displacements and decrease the damage losses due to earthquakes, a displacement-based design (DBD) approach has been developed and generally accepted by researches and engineers [2-6]. In the DBD procedure, the inelastic displacement demand of nonlinearly damped structures is often modeled by the maximum elastic displacement of the equivalent linear system based on the concept of effective stiffness and equivalent viscous damping (EVD) ratio [7]. Therefore, one of the key issues in the DBD procedure is the accurate estimation of EVD of the equivalent linear systems. The concept of EVD was first proposed by Jacobsen [8]. In his pioneering study, Jacobsen proposed that the EVD ratio is determined by equating the energy dissipated in one cycle of a steady-state response of the nonlinear system to that of the equivalent linear system.

Since the equivalent damping approach was proposed, extensive researchers have studied this concept and proposed different EVD ratio models for estimating the energy dissipation capacity of RC structures and members subjected to seismic excitations. Rosenblueth and Herrera [9] defined the secant stiffness at the maximum deformation as the basis for selecting period shift, in which the EVD ratio equation was derived based on the ratio between the elastic stored energy and the dissipated energy by the elastoplastic hysteretic model. This equation has been adopted by ATC-40 [10] and FEMA 440 [11] for pushover analysis of RC structures. Similarly, Kowalsky et al. [12] derived an equation of the equivalent damping ratio based on the Takeda hysteretic model [13]. Pekcan et al. [14] proposed a formulation of the equivalent damping ratio considering the energy absorption efficient factor which reflects the EVD properties of nonlinear viscous dampers. In addition, some empirical models have been proposed based on the results of time-history analyses and physical experiments. Gülkan and Sozen [15] proposed an empirical equation of the equivalent damping ratio from physical experiments based on the principle of equal energy dissipation between the inelastic system and equivalent linear system. Iwan [16] derived empirical equations to estimate the equivalent damping ratio of structures based on results from time-history analyses for a number of SDOF hysteretic systems. Kwan and Billington [17] proposed an equation of the 
EVD ratio by carrying out extensive time-history analyses of SDOF systems with six types of hysteretic behavior. In their proposed equation, the influence of hysteretic behavior is incorporated, which is not considered in the equation developed by Iwan. Priestley et al. [2] proposed different EVD ratio equations corresponding to different structures and members based on theoretical analysis and experimental data. Rodrigues et al. [18] proposed an equivalent damping ratio model of RC columns based on the pseudostatic test with a biaxial loading path. Liu and Zhang [19] presented an equivalent viscous damping model for base-isolated SDOF systems. Moreover, Chisari et al. and Bedon et al. [20, 21] studied the effect of mechanical properties of seismic isolators and $\mathrm{RC}$ bridges on the loading rate. It is shown that the mechanical properties of seismic isolators and RC are markedly sensitive to the loading rate, and the results of seismic analyses are also sensitive to input properties. This suggests that the influence of the external input should be considered as far as possible in establishing the EVD model for predicting energy dissipation capacity of structures. Although many equivalent damping ratio models have been presented, if these models are not capable to represent the hysteretic energy dissipation characteristics of nonlinear systems, the maximum inelastic displacement demand will not be accurately evaluated. Therefore, the accuracy of the existing equivalent damping ratio models for different hysteretic models has been analyzed by many researchers such as Miranda and RuizGarcía [22], Blandon and Priestley [23], Dwairi et al. [24], Jara et al. [4], and Khan et al. [6]. The analysis results show that the maximum inelastic displacement of structures may be overestimated or underestimated due to the significant errors of equivalent damping ratio values; hence, the accuracy of the existing equivalent damping ratio models in predicting the energy dissipation capacity of structures needs to be improved.

In view of the abovementioned facts, the rationality and accuracy of the equivalent damping ratio models for estimating the energy dissipation capacity of RC structures and members are still open questions. Moreover, hysteretic behavior of structural members plays an important role in determining the EVD ratio models. The more realistic is the hysteretic model adopted to describe the hysteretic behavior of members, the higher is the accuracy obtained from the EVD model. Therefore, to obtain the rational EVD ratio model for flexure critical RC columns, the reasonable hysteretic loop models for describing the behavior of flexure critical RC members should be proposed. Although several hysteretic models, such as Takeda and elastoplastic, were adopted for establishing the EVD ratio models of flexure critical RC members based on the equivalent linearization method in the previous researches, the results indicate that the proposed models need to be complemented with some kind of corrections to predict the EVD. In fact, the designed RC columns will experience two main kinds of failure under seismic loading, that is, flexure failure (referred to as flexure critical columns) and shear failure after flexure yielding (referred to as flexure-shear critical columns). The hysteretic properties of the two types of abovementioned columns are different, and the flexure critical columns have minor pinching effect, strength decrease, and stiffness degradation due to flexure effects in the seismic response. Therefore, to describe the hysteretic behavior of flexure critical RC columns reasonably, an analytical expression of the hysteretic loop for predicting the hysteretic behavior of flexure critical RC columns is proposed. Furthermore, the EVD ratio model for flexure critical RC columns is also derived based on the proposed hysteretic loop expression.

In this study, the hysteretic loop expression and EVD ratio model for flexure critical RC columns are presented based on the equivalent linearization method and the hysteresis response data of flexure critical RC columns from the PEER database [25]. Also, the pushover analysis on the well-confined $\mathrm{RC}$ bridge with a single pier is taken as an example to show how the proposed EVD ratio model is used in seismic analysis of the structures. Note that, the research of the hysteretic loop model and EVD ratio model for flexure-shear critical RC columns is beyond the scope of this paper, but the companion research conducted by Zhang et al. [26] has reported the corresponding models for flexure-shear critical RC members.

\section{Hysteretic Loop Model of Flexure Critical Column}

2.1. Expression of the Hysteretic Curve. The energy dissipation capacity of RC structures and members depends on the hysteretic loop model. So, a good description of the hysteretic loop is paramount important for developing the EVD ratio model. For the flexure critical RC columns, the hysteretic behavior is characterized by a full hysteretic loop, minor pinching effect, and strength degradation under cyclic loading. These are also supported by the experimental data of flexure critical RC columns from the PEER database. Based on these characteristics, a model shown in Figure 1(a) is developed to describe the hysteretic loops of the flexure critical RC column. As illustrated in Figure 1(a), it is assumed that both the points $A$ and $D$, corresponding, respectively, to the peak displacements of positive and negative directions are on the envelop curves of hysteretic loops, and the lower and the upper branches of the hysteretic loops are symmetrical about the origin of the coordinate system. So, once the equation of one branch is determined, then the other is also determined by symmetry. As for the envelop curve of the flexure critical columns, it can be developed by sectional analysis technology and the simplified plastic hinge model. To analyze the capacity of lateral loading and deformation of flexure critical RC columns with different design parameters in the same level, the lateral displacement $d$ and load $F$ of the columns are normalized by the yielding displacement and load, respectively, as follows:

$$
\begin{aligned}
& x=\frac{d}{d_{\mathrm{y}}}, \\
& y=\frac{F}{F_{\mathrm{y}}},
\end{aligned}
$$

where $d_{\mathrm{y}}$ and $F_{\mathrm{y}}$ are the yield displacement and yield load of the columns and determined according to the equal energy method suggested by the EN 1998-1 [27], as shown in Figure 2. As a result, the hysteretic loop of the flexure critical 


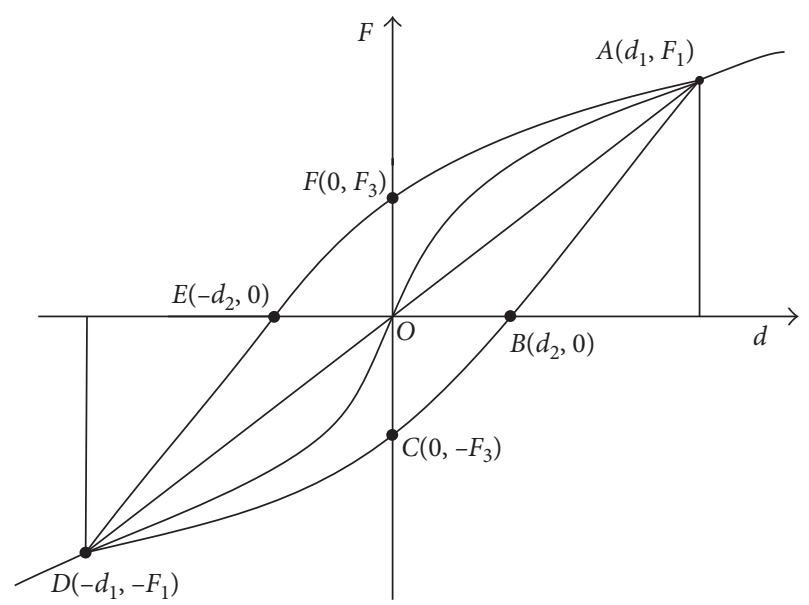

(a)

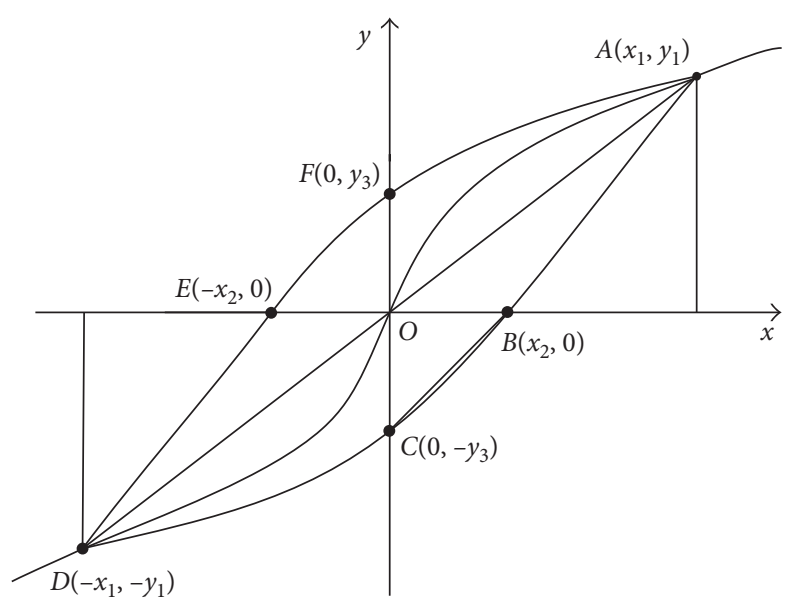

(b)

Figure 1: Proposed hysteretic loop model. (a) $F-d$. (b) $y-x$.

$\mathrm{RC}$ column can be expressed by the normalized later displacement $x$ and force $y$, as shown in Figure 1(b).

To facilitate the development of hysteretic loop expression, the semihysteretic loop curve $A B C D$ in Figure 1 (b) is investigated. The mathematical expression of the curve can be suggested in a rational format as follows:

$$
y=\frac{a_{1}+b_{1} x}{1+c_{1} x+c_{2} x^{2}}
$$

where $a_{1}, b_{1}, c_{1}$, and $c_{2}$ are the empirical coefficients and determined based on the experimental results of RC columns.

Owing to the key points such as $A\left(x_{1}, y_{1}\right), B\left(x_{2}, 0\right), C(0$, $\left.-y_{3}\right)$, and $D\left(-x_{1},-y_{1}\right)$, which are on the normalized lower branch of the hysteretic loop, the following equations can be derived:

$$
\begin{aligned}
\frac{a_{1}+b_{1} x_{1}}{1+c_{1} x_{1}+c_{2} x_{1}^{2}} & =y_{1}, \\
\frac{a_{1}+b_{1} x_{2}}{1+c_{1} x_{2}+c_{2} x_{2}^{2}} & =0, \\
a_{1} & =-y_{3}, \\
\frac{a_{1}-b_{1} x_{1}}{1-c_{1} x_{1}+c_{2} x_{1}^{2}} & =-y_{1} .
\end{aligned}
$$

By solving, (3) leads to

$$
\begin{aligned}
& a_{1}=-y_{3}, \\
& b_{1}=\frac{y_{3}}{x_{2}}, \\
& c_{1}=-\frac{y_{3}}{y_{1}} \times \frac{1}{x_{1}}, \\
& c_{2}=\frac{y_{3}}{y_{1}} \times \frac{1}{x_{1} x_{2}}-\frac{1}{x_{1}^{2}} .
\end{aligned}
$$

By substituting $a_{1}, b_{1}, c_{1}$, and $c_{2}$ into (2), the normalized equation of the lower branch of the hysteretic loop is derived as follows:

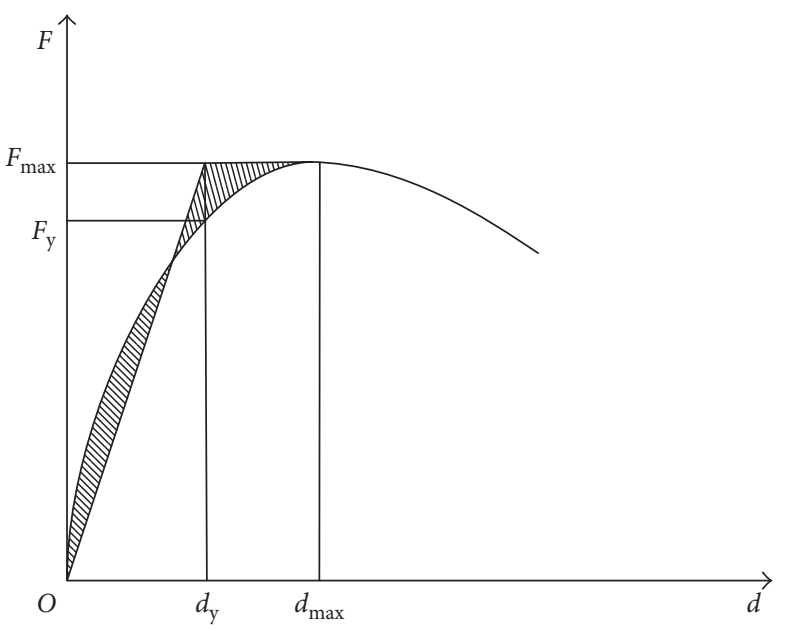

FIgURE 2: Determination of the yield point.

$$
\begin{aligned}
y= & \frac{-y_{3}\left(1-\left(x / x_{2}\right)\right)}{1-\left(y_{3} / y_{1}\right) \times\left(x / x_{1}\right)-\left(-\left(y_{3} / y_{1}\right) \times\left(x_{1} / x_{2}\right)+1\right)\left(x / x_{1}\right)^{2}} \\
& \cdot\left(-x_{1} \leq x \leq x_{1}\right) .
\end{aligned}
$$

Similarly, the normalized equation of the upper branch of the hysteretic loop (i.e., semihysteretic loop curve $s$ ) can also be established. Consequently, the complete normalized equation of the hysteretic loop can be expressed as

$$
\begin{aligned}
y= & \frac{y_{3}\left( \pm 1+\left(x / x_{2}\right)\right)}{1 \pm\left(y_{3} / y_{1}\right) \times\left(x / x_{1}\right)-\left(1-\left(y_{3} / y_{1}\right) \times\left(x_{1} / x_{2}\right)\right)\left(x / x_{1}\right)^{2}} \\
& \cdot\left(-x_{1} \leq x \leq x_{1}\right),
\end{aligned}
$$

where the plus and minus signs are relative to the upper and lower branches of the hysteretic loop, respectively. The plus sign is for the upper branch, and the minus sign is for the lower branch. So, once the points $A\left(x_{1}, y_{1}\right),\left(x_{2}, 0\right), C\left(0,-y_{3}\right)$, 


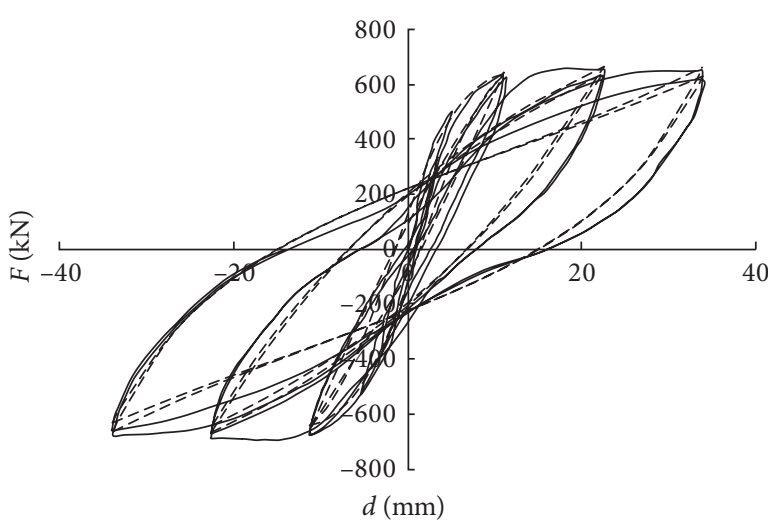

— Experiment

--- Equation (6)

(a)

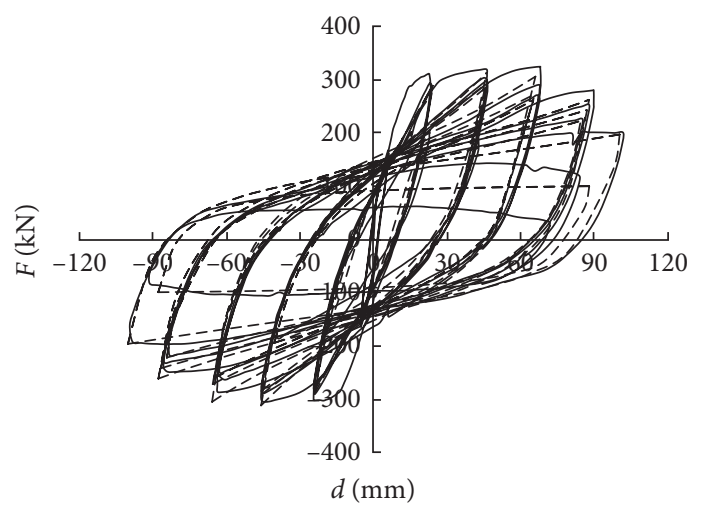

- Experiment

--- Equation (6)

(c)

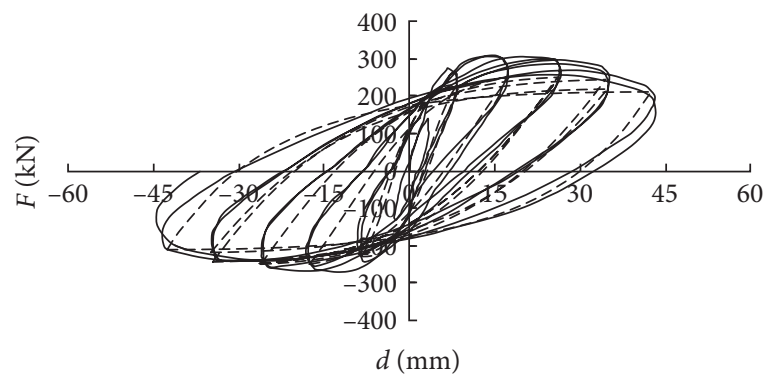

- Experiment

--- Equation (6)

(e)

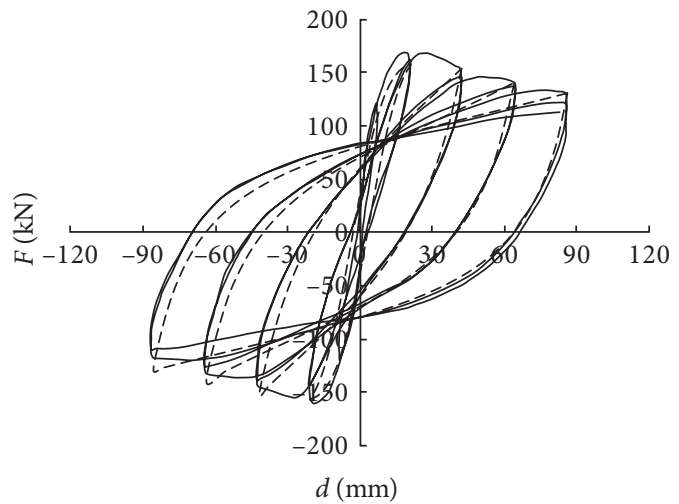

- Experiment

--- Equation (6)

(b)

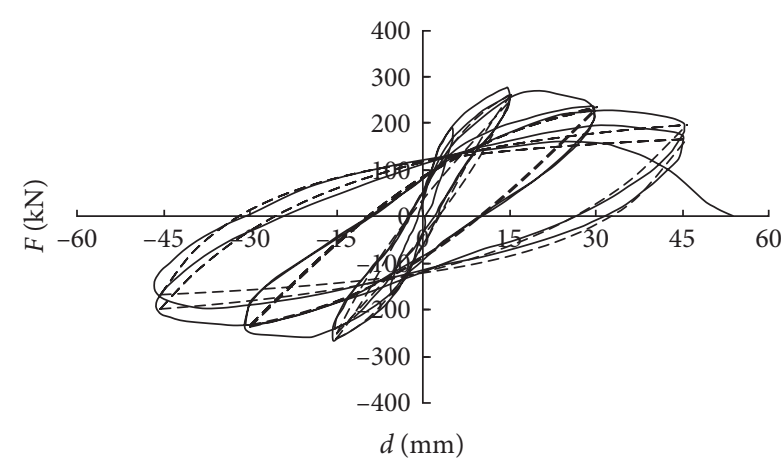

- Experiment

--- Equation (6)

(d)

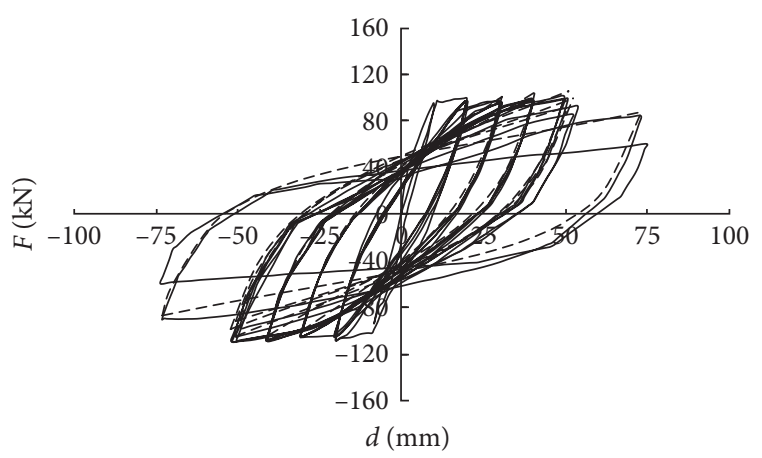

- Experiment

--- Equation (6)

(f)

Figure 3: Comparison of hysteretic loops between the test and that predicted by (6). (a) Gill et al. (No. 1). (b) Tanaka and Park (No. 2). (c) Saatcioglu and Ozcebe (U4). (d) Soesianawati et al. (No. 3). (e) Watson and Park (No. 9). (f) Ohno and Nishioka (L3).

and $D\left(-x_{1},-y_{1}\right)$ are determined, the curves of the hysteretic loop for the flexure critical RC columns can be described and generated by (6).

To verify the effectiveness of (6) in describing the hysteretic loop of flexure critical RC columns, the results by (6) and the experimental results by different researchers in the
PEER column database are compared and a good agreement is observed, as demonstrated in Figure 3. It should be noted that although the lower branch and the upper branch of the hysteretic loop are assumed symmetrical about the origin of the coordinate system, the fact is that the behavior may by asymmetric due to the variability of material properties, the 
TABLE 1: Selected columns with square cross section from the PEER database [25].

\begin{tabular}{|c|c|c|}
\hline Number & Designation & \\
\hline 1 & \multirow{4}{*}{ Gill et al. (1979) } & No. 1 \\
\hline 2 & & No. 2 \\
\hline 3 & & No. 3 \\
\hline 4 & & No. 4 \\
\hline 5 & \multirow{2}{*}{ Ang et al. (1981) } & No. 3 \\
\hline 6 & & No. 4 \\
\hline 7 & \multirow{4}{*}{ Soesianawati et al. (1986) } & No. 1 \\
\hline 8 & & No. 2 \\
\hline 9 & & No. 3 \\
\hline 10 & & No. 4 \\
\hline 11 & \multirow{2}{*}{ Zahn et al. (1986) } & No. 7 \\
\hline 12 & & No. 8 \\
\hline 13 & \multirow{5}{*}{ Watson and Park (1989) } & No. 5 \\
\hline 14 & & No. 6 \\
\hline 15 & & No. 7 \\
\hline 16 & & No. 8 \\
\hline 17 & & No. 9 \\
\hline 18 & \multirow{8}{*}{ Tanaka and Park (1990) } & No. 1 \\
\hline 19 & & No. 2 \\
\hline 20 & & No. 3 \\
\hline 21 & & No. 4 \\
\hline 22 & & No. 5 \\
\hline 23 & & No. 6 \\
\hline 24 & & No. 7 \\
\hline 25 & & No. 8 \\
\hline 26 & Zhou et al. (1987) & No. $214-08$ \\
\hline 27 & \multirow{6}{*}{ Kanda et al. (1988) } & 85STC-1 \\
\hline 28 & & 85STC-2 \\
\hline 29 & & 85STC-3 \\
\hline 30 & & 85PDC-1 \\
\hline 31 & & 85PDC-2 \\
\hline 32 & & 85PDC-3 \\
\hline 33 & \multirow{5}{*}{ Atalay and Penzien (1975) } & No. 1S1 \\
\hline 34 & & No. $2 S 1$ \\
\hline 35 & & No. $3 S 1$ \\
\hline 36 & & No. $4 \mathrm{~S} 1$ \\
\hline 37 & & No. $5 \mathrm{~S} 1$ \\
\hline 38 & \multirow{5}{*}{ Atalay and Penzien (1975) } & No. $6 \mathrm{~S} 1$ \\
\hline 39 & & No. 9 \\
\hline 40 & & No. 10 \\
\hline 41 & & No. 11 \\
\hline 42 & & No. 12 \\
\hline 43 & \multirow{3}{*}{ Saatcioglu and Ozcebe (1989) } & U1 \\
\hline 44 & & $\mathrm{U} 3$ \\
\hline 45 & & $\mathrm{U} 4$ \\
\hline 46 & Nosho et al. (1996) & No. 1 \\
\hline 47 & \multirow{7}{*}{ Saatcioglu and Grira (1999) } & BG-1 \\
\hline 48 & & BG-2 \\
\hline 49 & & $\mathrm{BG}-3$ \\
\hline 50 & & BG-4 \\
\hline 51 & & BG-5 \\
\hline 52 & & BG-7 \\
\hline 53 & & BG-8 \\
\hline 54 & \multirow{4}{*}{ Matamoros et al. (1999) } & $\mathrm{C} 5-20 \mathrm{~N}$ \\
\hline 55 & & C5-20S \\
\hline 56 & & $\mathrm{C} 5-40 \mathrm{~N}$ \\
\hline 57 & & C5-40S \\
\hline
\end{tabular}

TABle 1: Continued.

\begin{tabular}{lcc}
\hline Number & Designation \\
\hline 58 & & C1-1 \\
59 & C1-2 \\
60 & C1-3 \\
61 & Mo and Wang (2000) & C2-1 \\
62 & & C2-3 \\
63 & C3-1 \\
64 & & C3-2 \\
65 & & C3-3 \\
66 & Bechtoula, Kono, Arai, and & D1N30 \\
\hline 67 & Watanabe (2002) & L1N60 \\
68 & & L1N6B \\
69 & & Test 1 (JSCE-4) \\
70 & Takemura and Kawashima (1997) & Test 2 (JSCE-5) \\
\hline 71 & & Test 3 (JSCE-6) \\
72 & & \\
73 &
\end{tabular}

error arising from the test equipment and device, and the degradation of strength. In view of this, the parameters $x_{1}$, $y_{1}, x_{2}$, and $y_{3}$ are determined by taking the average of their values corresponding to the points on the lower branch and upper branch of the hysteretic loop. As indicated in Figure 3, (6) describes well the characteristics of hysteretic response with minor pitching effect and strength degradation for the flexure critical RC columns.

2.2. Quantification of the Parameters of the Equation. As shown in (6), the pattern of the hysteretic loop for flexure critical columns depends on the values of parameters $x_{1}, y_{1}$, $x_{2}$, and $y_{3}$. Therefore, it is crucial to quantify their values for modeling the hysteretic loops. As stated above, the points $A\left(x_{1}, y_{1}\right)$ and $D\left(-x_{1},-y_{1}\right)$ on the envelope curves are, respectively, corresponding to the maximum positive and negative displacements of the columns in one cycle, which can be determined by the skeleton curve (i.e., the loaddisplacement relationship under monotonic loading) of the hysteretic loop of the columns. Hence, the parameters $x_{1}$ and $y_{1}$ can be regarded as the known variables, that is, $x_{1}=\mu$, and $y_{1}=f\left(x_{1}\right)=f(\mu)$, where $\mu$ is the relative displacement ductility factor of the columns and defined as the ratio of the maximum lateral displacement $d_{1}$ to the yield displacement $d_{\mathrm{y}}$ in one cycle, that is, $\mu=d_{1} / d_{\mathrm{y}}=x_{1}$. As for the parameters, the corresponding equations can be derived according to the geometrical relationships of points $B\left(x_{2}, 0\right), C\left(0,-y_{3}\right)$, $A\left(x_{1}, y_{1}\right)$, and $D\left(-x_{1},-y_{1}\right)$. To determine the abovementioned parameters, 73 flexure critical RC columns with square cross section were selected from the PEER database as tabulated in Table 1 for analysis. The criterion of selection is that the hysteretic loops should be "regular" and their lower and upper branches are approximately symmetric about the origin of the coordinate system. Figure 4 plots the relationship between $x_{2}$ and $x_{1}$, where $x_{2}$ is the normalized residual displacement corresponding to the lateral load reducing to zero. The following power function is derived through nonlinear regression analysis for describing the relationship between $x_{2}$ and $x_{1}$ : 


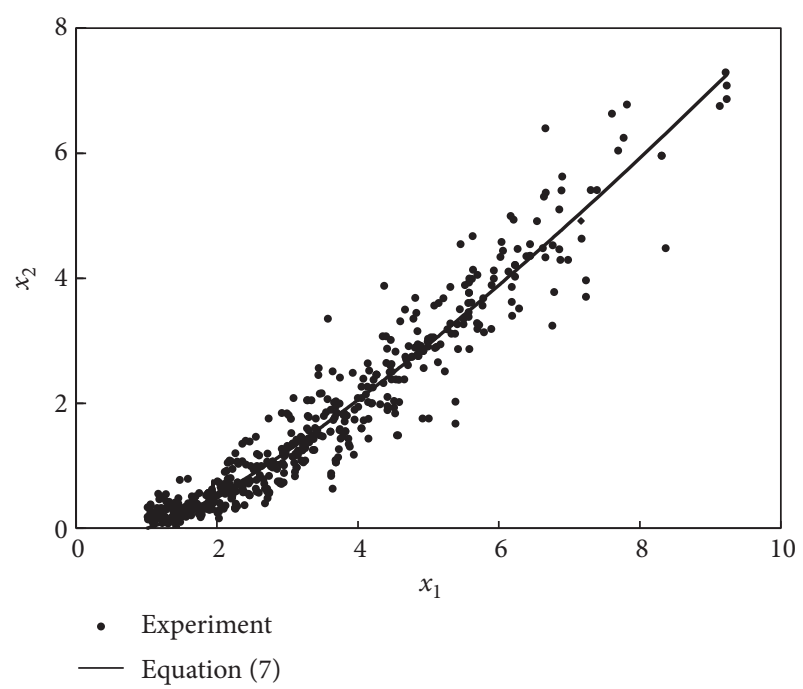

Figure 4: Relationship between $x_{2}$ and $x_{1}$.

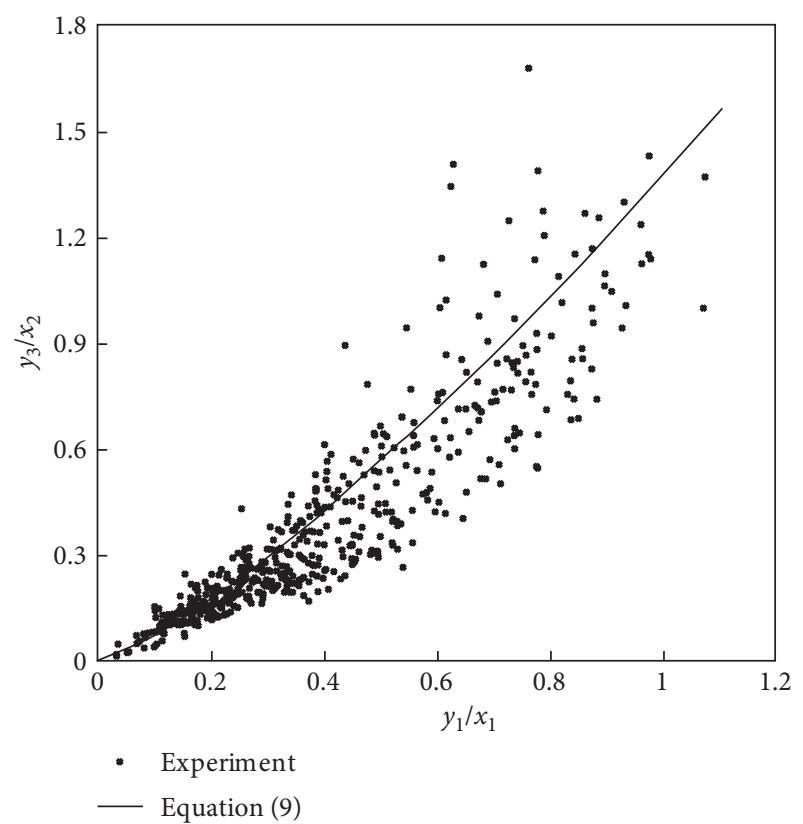

FIGURE 5: Relationship between $y_{3} / x_{2}$ and $y_{1} / x_{1}$.

$$
x_{2}=0.52\left(x_{1}-1\right)^{1.25}
$$

or

$$
\frac{x_{2}}{x_{1}}=\frac{\lambda}{\mu}=\frac{0.52(\mu-1)^{1.25}}{\mu},
$$

where $\mu$ is the relative displacement ductility factor of the columns, $\mu=d_{1} / d_{\mathrm{y}}=x_{1}$, and $\lambda$ is the normalized residual lateral displacement, $\lambda=x_{2}$.

To illustrate the relationship between the reloaded secant stiffness and the secant stiffness corresponding to displacement $d_{1}$ of the columns under cyclic loading, the variation tendency between $y_{3} / x_{2}$ (i.e., the slope of the line BC in Figure 1(b)) and $y_{1} / x_{1}$ (i.e., the slope of the line $O A$ in Figure 1(b)) is shown in Figure 5. Based on this tendency, the following equation is formulated:

$$
\frac{y_{3}}{x_{2}}=1.25\left(\frac{y_{1}}{x_{1}}\right)^{1.18} .
$$

Combining (1) and (9), $y_{3} / x_{2}$ can be further rewritten as follows:

$$
\begin{aligned}
\frac{y_{3}}{x_{2}} & =1.25\left(\frac{F_{1} / F_{\mathrm{y}}}{d_{1} / d_{\mathrm{y}}}\right)^{1.18}=1.25\left(\frac{F_{1}}{d_{1}} \times \frac{d_{\mathrm{y}}}{F_{\mathrm{y}}}\right)^{1.18} \\
& =1.25\left(\frac{k_{\mathrm{sec}}}{k_{\mathrm{y}}}\right)^{1.18},
\end{aligned}
$$

where $k_{\text {sec }}$ is the secant stiffness of the columns corresponding to displacement $d_{1}$ and $k_{\mathrm{y}}$ is the yield stiffness.

Combining (8) and (10), the parameter $\alpha=y_{3} / y_{1}$ can be derived as follows:

$$
\begin{aligned}
\alpha & =\frac{y_{3}}{y_{1}}=1.25\left(\frac{k_{\mathrm{sec}}}{k_{\mathrm{y}}}\right)^{1.18} \frac{x_{2}}{y_{1}}=1.25\left(\frac{k_{\mathrm{sec}}}{k_{\mathrm{y}}}\right)^{1.18} \frac{x_{1}}{y_{1}} \times \frac{x_{2}}{x_{1}}, \\
& =\frac{0.65(\mu-1)^{1.25}}{\mu}\left(\frac{k_{\mathrm{sec}}}{k_{\mathrm{y}}}\right)^{1.18} \frac{x_{1} d_{\mathrm{y}}}{y_{1} F_{\mathrm{y}}} \times \frac{F_{\mathrm{y}}}{d_{\mathrm{y}}}, \\
& =\frac{0.65(\mu-1)^{1.25}}{\mu}\left(\frac{k_{\mathrm{sec}}}{k_{\mathrm{y}}}\right)^{1.18} \frac{d_{1}}{F_{1}} \times \frac{F_{\mathrm{y}}}{d_{\mathrm{y}}} \\
& =\frac{0.65(\mu-1)^{1.25}}{\mu}\left(\frac{k_{\mathrm{sec}}}{k_{\mathrm{y}}}\right)^{1.18} \frac{k_{\mathrm{y}}}{k_{\mathrm{sec}}} \\
& =\frac{0.65(\mu-1)^{1.25}}{\mu}\left(\frac{k_{\mathrm{sec}}}{k_{\mathrm{y}}}\right)^{0.18} \cdot
\end{aligned}
$$

According to the discussion above, the parameters $x_{2} / x_{1}$ and $y_{3} / y_{1}$ can be quantified utilizing (8) and (11), respectively. The envelop curve of the hysteretic loop for flexure critical RC columns can be established by the sectional analysis technology and plastic hinge method. Then, the hysteretic loops of flexure critical RC columns can be predicted by (6) if the relative displacement ductility factor $\mu$ is given.

\section{Determination of Equivalent Damping Ratio of Flexure Critical Columns}

In general, the equivalent damping ratio of the structure or member is depicted as the sum of viscous damping ratio $\zeta_{0}$ and the equivalent part $\zeta_{\text {hys }}$, that is,

$$
\zeta_{\text {eff }}=\zeta_{0}+\zeta_{\text {hys }}
$$

where $\zeta_{0}$ is the viscous damping and generally taken as $5 \%$ for reinforced concrete members and $\zeta_{\text {hys }}$ is the equivalent viscous damping and derived from the hysteretic energy dissipated by the structure or member under a complete loading cycle as shown in Figure 1.

In this study, the rationality and accuracy of equivalent viscous damping $\zeta_{\text {hys }}$ for flexure critical RC columns are focused on, and Jacobsen's method including the proposed hysteretic 
loop model is adopted to determine $\zeta_{\text {hys }}$ due to the equivalent concept simplicity. The expression can be given as follows:

$$
\zeta_{\text {hys }}=\frac{E_{\text {hys }}}{4 \pi E_{\mathrm{el}}},
$$

where $E_{\text {hys }}$ is the hysteretic energy dissipation in the columns during a complete loading cycle and is defined by the area of a full and closed hysteretic loop, as illustrated in Figure 6, and $E_{\mathrm{el}}$ is the elastic displacement energy corresponding to the maximum displacement in the complete loading cycle and is expressed as follows:

$$
E_{\mathrm{el}}=\frac{1}{2} x_{1} y_{1}
$$

As shown in Figure 6, the area enclosed by the full hysteretic loop can be computed as two times the difference of area enclosed by EFAH and that by DEG. By means of (6) and (14), the hysteretic energy $E_{\text {hys }}$ can be evaluated by the following integration:

$$
\begin{aligned}
E_{\mathrm{hys}} & =2\left(S_{\mathrm{EFAH}}-S_{\mathrm{DEG}}\right) \\
& =2 S_{\mathrm{EFAB}},=2 \int_{-x_{1}}^{x_{1}} y_{\mathrm{DEFA}} d x \\
& =2 \int_{-x_{1}}^{x_{1}} \frac{y_{3}\left(1+\left(x / x_{2}\right)\right)}{1+\left(y_{3} / y_{1}\right) \times\left(x / x_{1}\right)-\left(1-\left(y_{3} / y_{1}\right) \times\left(x_{1} / x_{2}\right)\right)\left(x / x_{1}\right)^{2}} d x, \\
& =2 \int_{-x_{1}}^{x_{1}} \frac{y_{3}\left(1+\left(x / x_{2}\right)\right)}{1+\alpha\left(x / x_{1}\right)-(1-\alpha(\mu / \lambda))\left(x / x_{1}\right)^{2}} d x .
\end{aligned}
$$

The result of (15) can be found in the Appendix. By defining $\beta=\alpha^{2}+4-(4 \alpha \mu / \lambda)$ and substituting (15), (13), and (12) in (11), the following three-piece equations of the equivalent damping ratio can be derived:

If $\beta<0$,

$$
\begin{aligned}
\zeta_{e f f}= & \zeta_{0}+\frac{\left[2 \alpha(\lambda / \mu)-\alpha^{2}\right]}{\pi \sqrt{|\beta|}((\lambda / \mu)-\alpha)} \arctan \frac{-2+\alpha(1+2(\mu / \lambda))}{\sqrt{|\beta|}} \\
& -\arctan \frac{2+\alpha(1-2(\mu / \lambda))}{\sqrt{|\beta|}}-\frac{\alpha}{2 \pi((\lambda / \mu)-\alpha)} \ln \frac{\mu+\lambda}{\mu-\lambda} .
\end{aligned}
$$

If $\beta>0$,

$$
\begin{aligned}
\zeta_{\text {eff }}= & \zeta_{0}+\frac{\left(2 \alpha(\lambda / \mu)-\alpha^{2}\right)}{2 \pi \sqrt{\beta}((\lambda / \mu)-\alpha)} \ln \left|\frac{\alpha^{2}-[2(1-\alpha(\mu / \lambda))+\sqrt{\beta}]^{2}}{\alpha^{2}-[2(1-\alpha(\mu / \lambda))-\sqrt{\beta}]^{2}}\right| \\
& -\frac{\alpha}{2 \pi((\lambda / \mu)-\alpha)} \ln \frac{\mu+\lambda}{\mu-\lambda} .
\end{aligned}
$$

If $\beta=0$,

$$
\zeta_{\mathrm{eff}}=\zeta_{0}+\frac{4}{\pi \alpha}\left(\frac{\mu}{\lambda}-1\right) \ln \frac{2+\alpha}{2-\alpha} .
$$

From $(16 a)-(16 c), \zeta_{0}$ is taken as $5 \%$. To illustrate the accuracy of the proposed model for predicting the equivalent viscous damping, the results of the equivalent damping ratio predicted by (16a)-(16c) and other equations

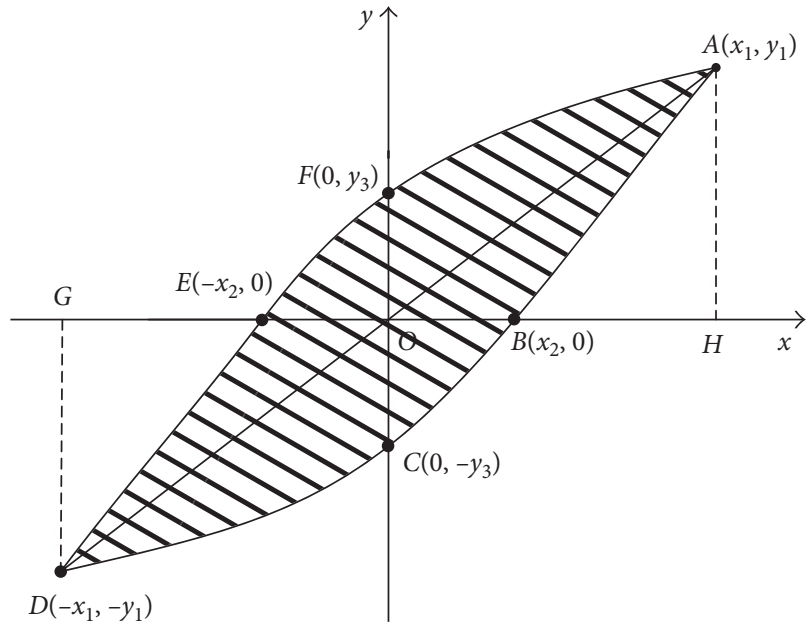

Figure 6: Hysteretic energy dissipation in the column.

are, respectively, compared with those calculated according to the experimental data of flexure critical RC columns from the PEER database, as shown in Figure 7. It can be seen that a good agreement is achieved between the results of the EVD ratio of columns predicted by (16a)-(16c) and those derived from experimental data. The accuracy of the results predicted by (16a)-(16c) is higher than that predicted by the other models tabulated in Table 2. It is also noted that the results predicted by (16a)-(16c) concentrate in the narrow strip region and ascend with increasing of the relative displacement ductility factor, but the ascending trend is not smooth due to the influences of the double parameters (i.e., ductility factor $\mu$ and the ratio of secant stiffness to yield stiffness $k_{\text {sec }} / k_{\mathrm{y}}$ ), which is different from the single parameter (e.g., ductility factor $\mu$ ) based models such as Rosenblueth's model and Kowalsky's model.

The statistical results of the ratio of the EVD ratio predicted by various models to those derived from experimental data of flexure critical RC columns are also tabulated in $\mathrm{Ta}$ ble 2. The comparison results indicate that the mean values of the EVD ratio predicted by the proposed model are approximately equal to that derived from experimental results and have little discreteness and high precision. On the contrary, some of the other models listed in Table 2 may overestimate or underestimate the EVD ratio of the columns.

To further illustrate the accuracy and rationality of the proposed two-parameter-based model for predicting the equivalent viscous damping ratio, the results of the equivalent damping ratio of flexure critical RC columns predicted by (16a)-(16c) and derived from the experimental data of the PEER database are compared in Figure 8. It can be seen that the points are distributed narrowly around the line at 45 degree, which again suggests that a good prediction of the equivalent damping ratio is achieved by the proposed model.

\section{Simplification of the Proposed Equivalent Viscous Damping Ratio Model}

According to the discussion of the above section, (16a)-(16c) predicts the EVD ratio for flexure critical RC columns with 


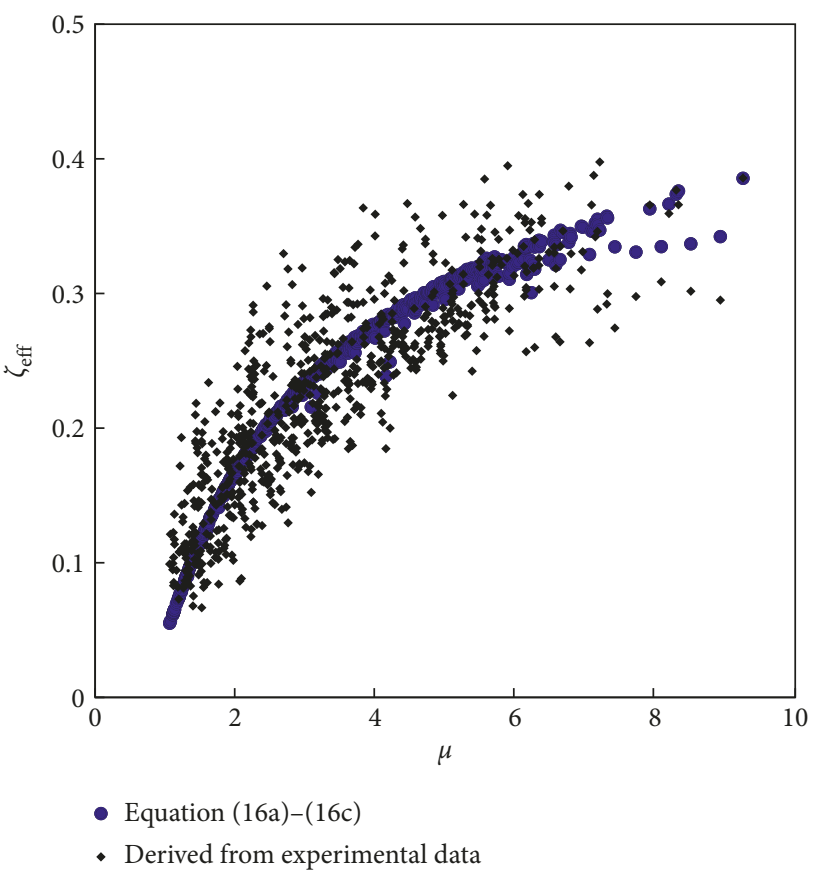

(a)

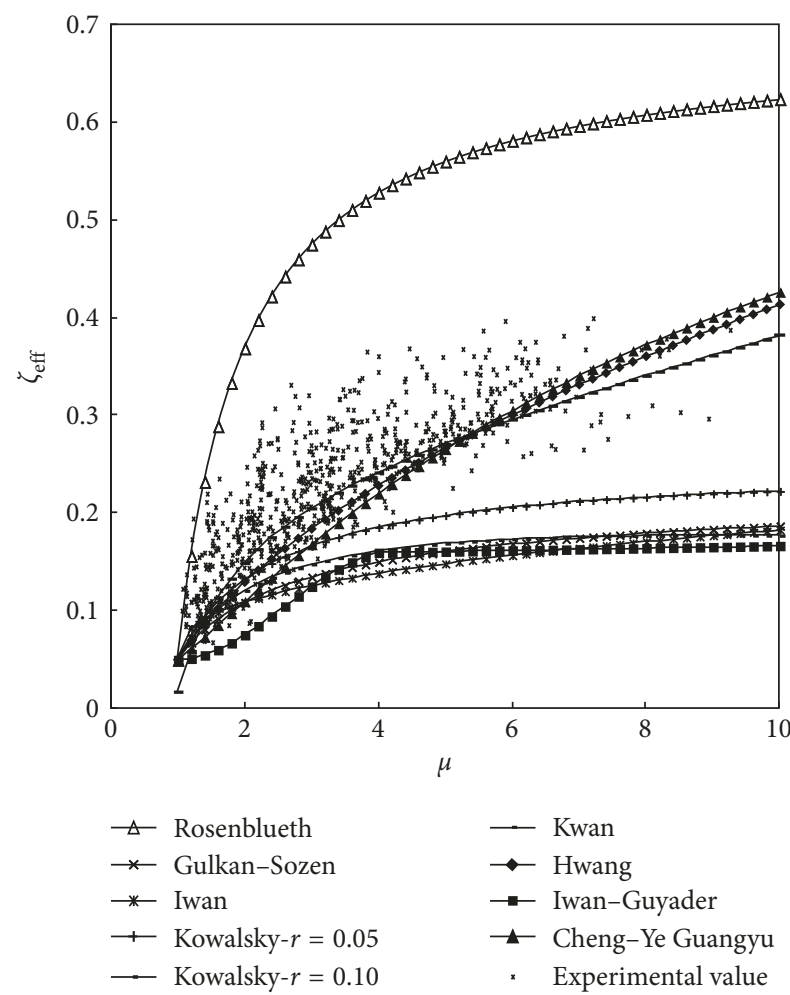

(b)

FIGURE 7: EVD ratio versus ductility factor: (a) predicted by (16a)-(16c); (b) predicted by the other equations.

TABLE 2: Statistical results of the EVD ratio predicted by various models to those derived from experimental data.

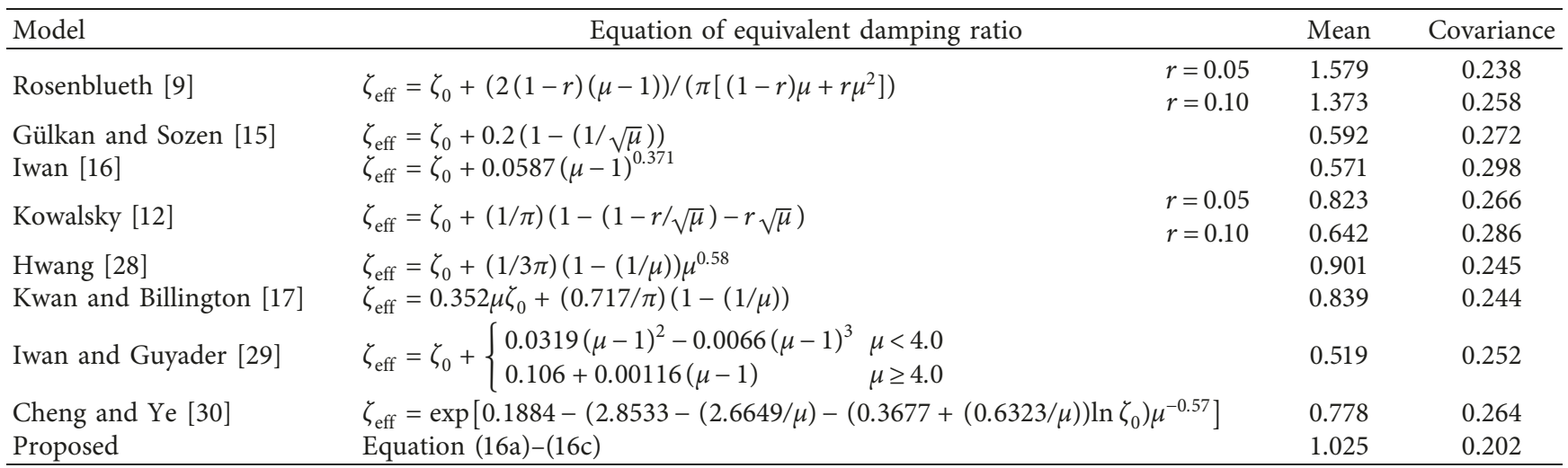

Note. $r$ is the ratio of postyield stiffness to yield stiffness of the envelop curve of the structures and members.

high reliability, but a tedious and complicated form of this equation would seriously limit its application. Hence, the simplified form of this equation is necessary to be proposed from the practical aspect.

The EVD ratio is a function of the ductility factor $\mu$ and the ratio of secant stiffness to yield stiffness $k_{\text {sec }} / k_{y}$ of flexure critical $\mathrm{RC}$ columns in (16a)-(16c). The geometrical relationship between the above two parameters is shown in Figure 9. It is obvious that the ratio of secant stiffness to yield stiffness $k_{\mathrm{sec}} / k_{\mathrm{y}}$ depends on the envelop curve of the hysteretic loop of the column. For different patterns of envelop curves, the variation of the ratio of secant stiffness to yield stiffness $k_{\text {sec }} / k_{\mathrm{y}}$ differs for the same ductility factor $\mu$. This means that the ratio of secant stiffness to yield stiffness $k_{\mathrm{sec}} / k_{\mathrm{y}}$ and ductility factor $\mu$ could not be treated as independent variables, and the relationship of them should be analyzed considering the effects of the pattern of envelop curves of flexure critical RC columns. Assuming the envelop curve of the column is bilinear with different ratios of postyield stiffness to yield stiffness $r$, as shown in Figure 10, the relationship between the ratio of secant stiffness to yield stiffness $k_{\mathrm{sec}} / k_{\mathrm{y}}$ and the ductility factor $\mu$ can be depicted as follows:

$$
\frac{k_{\mathrm{sec}}}{k_{\mathrm{y}}}=\frac{r(\mu-1)+1}{\mu},
$$

where $r$ is the ratio of postyield stiffness to yield stiffness of the columns. 


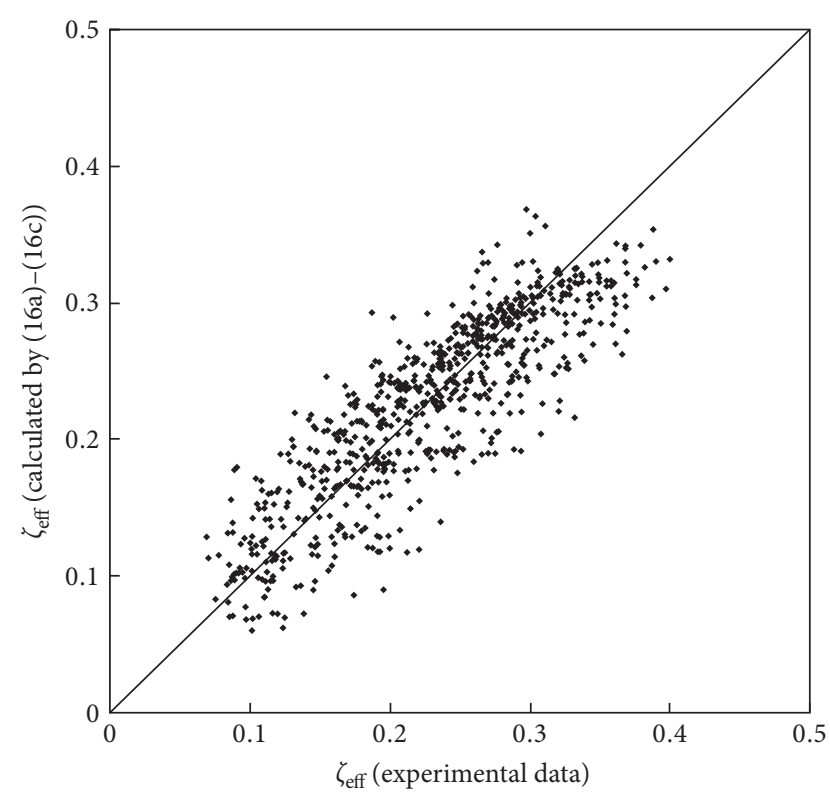

FIgure 8: Comparison of the EVD ratio predicted and derived from experimental data.

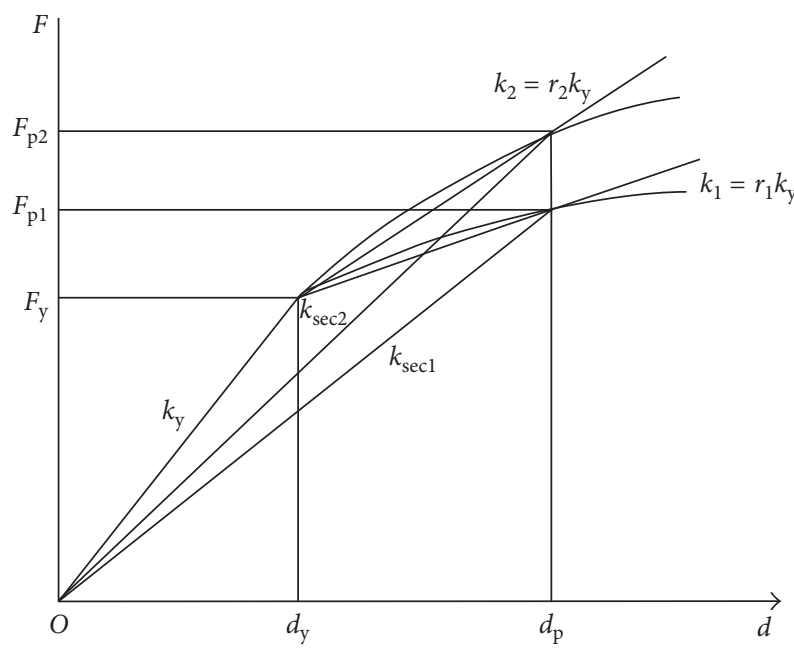

FIGURE 9: $k_{\mathrm{sec}} / k_{\mathrm{y}}$ versus $\mu\left(\mu=d_{\mathrm{p}} / d_{\mathrm{y}}\right)$.

Assuming the bilinear envelop curves of flexure critical RC columns with $r=-0.1,0.0,0.1,0.2$, and 0.3 , respectively, the corresponding EVD ratio with different displacement ductility factor $\mu$ can be predicted by (16a)-(16c) and is shown in Figure 11. Obviously, the EVD ratio is mainly associated with $k_{\mathrm{sec}} / k_{\mathrm{y}}$ and $\mu$, the relationships between the EVD ratio and ductility factor $\mu$ shown in Figure 11 can also be simplified by the nonlinear regression analysis technology, and the simplified equation is given as follows:

$$
\zeta_{\text {eff }}=\zeta_{0}+\frac{0.047}{1-0.77\left(k_{\mathrm{sec}} / k_{\mathrm{y}}\right)^{0.05}} \ln \mu .
$$

To further verify the accuracy of (18), which replaces (16a)(16c), for predicting the EVD ratio of flexure critical RC columns, the comparison of the results predicted by (18) and (16a)-(16c) is

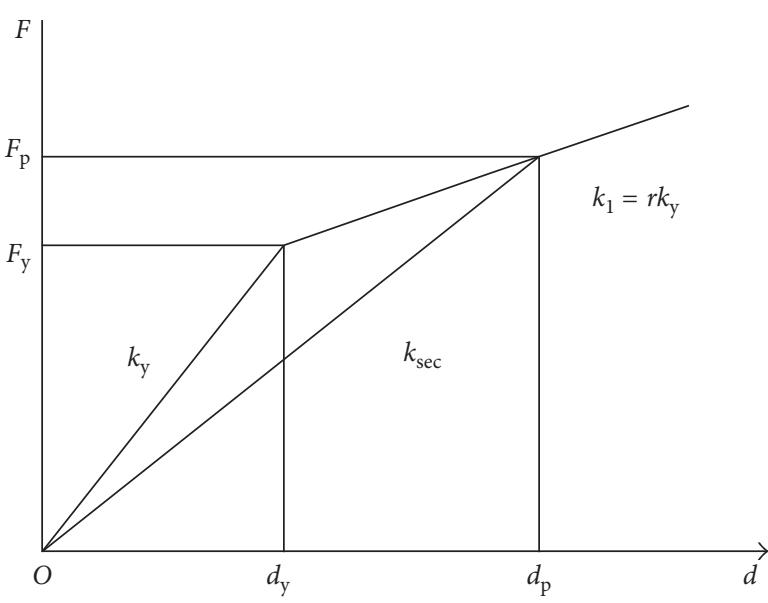

FIgURE 10: Bilinear envelop curve.

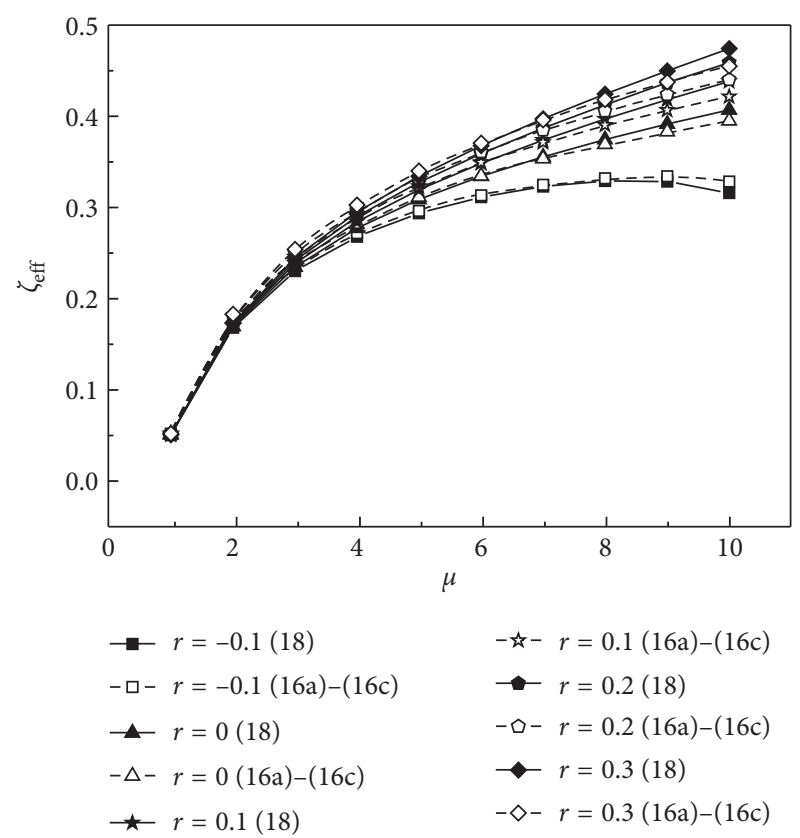

FIgURE 11: EVD ratio predicted by (16a)-(16c) and (18) versus ductility factor.

shown in Figure 12. It can be seen that (18) replicates well the results of (16a)-(16c).

It is noted that (18) is suitable for all the cases that the points at the envelop curve fall into the region swept by the line with $r=-0.1$ to 0.3 regardless of the pattern of the envelop curve. To verify this, the EVD ratios of the columns corresponding to three types of envelop curves with parabolic postyield branch shown in Figure 13 are calculated by (18) and (16a)-(16c) and compared in Figure 14. Again, it can be seen that the results of (18) are in a good agreement with the results of (16a)-(16c). Thus, (18) can be used for the relevant analysis instead of (16a)-(16c).

\section{Seismic Response Analysis of a Bridge Based on the Proposed Model}

An element level model for evaluating the EVD ratio of flexure critical RC columns is proposed based on theoretical 


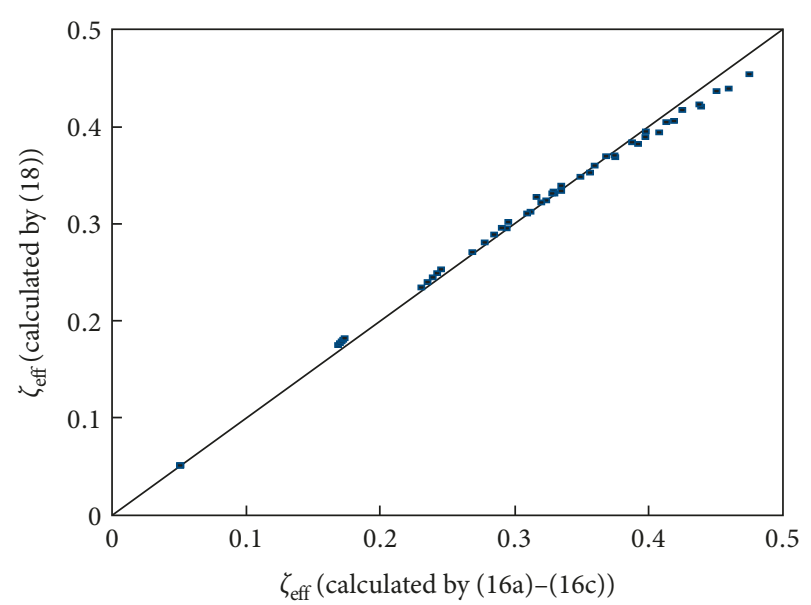

FIGURE 12: Comparison of the EVD ratio predicted by (18) and (16a)(16c).

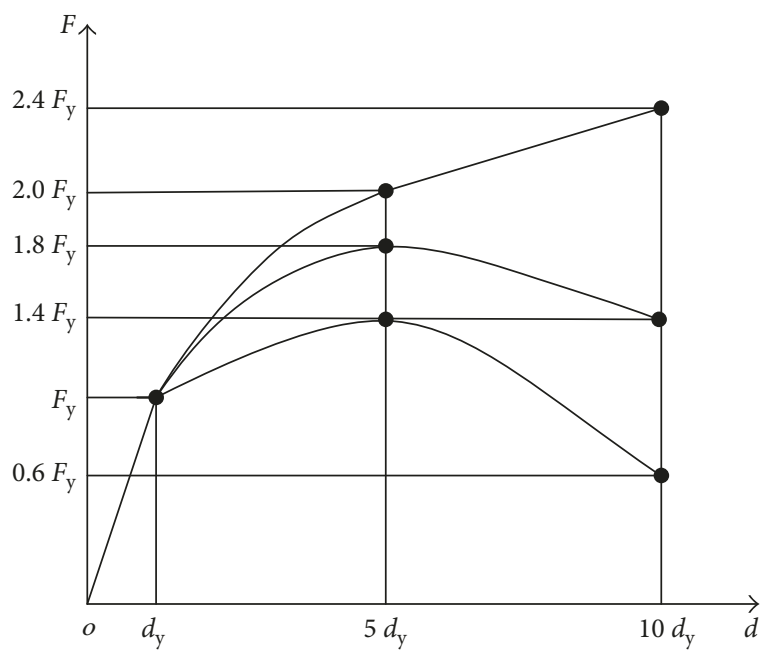

FIgURE 13: Envelop curve with parabolic postyield branch.

analysis and experimental data in this study. It can be used straightforwardly for the estimation of the EVD ratio of the single-column supported bridge structure because the energy dissipation capacity of plastic hinges formed in the column specimens is same as that for the bridge with a single-column pier. The following is an example to illustrate the application of the proposed EVD ratio model for seismic response analysis of a bridge based on the capacity spectrum method, and the analysis results are also compared with the results using the other models such as Rosenblueth's model and Kowalsky's model.

The RC bridge with a single pier is shown in Figure 15. The column pier is designed with properties as follows: bridge height $H$ is $6000 \mathrm{~mm}$; cross-sectional dimension is $1000 \mathrm{~mm} \times 1000 \mathrm{~mm}$; the concentrated mass $m$ of the bridge structure is $1.2 \times 10^{5} \mathrm{~kg}$; concrete compressive strength is $30 \mathrm{MPa}$; concrete cover depth is $30 \mathrm{~mm}$; twenty longitudinal reinforcements with a diameter of $28 \mathrm{~mm}$, yielding strength of $360 \mathrm{MPa}$, and ultimate strength of $500 \mathrm{MPa}$ are distributed uniformly in the four sides of the pier; and the yield strength

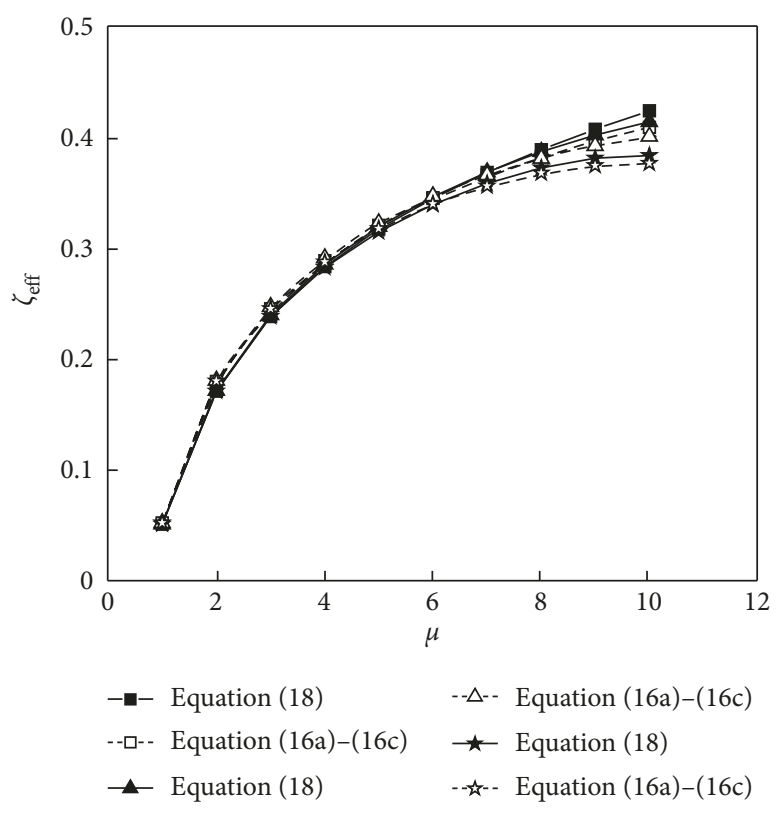

FIGURE 14: Comparison of EVD ratio predicted by (18) and (16a)(16c) based on the envelop curves in Figure 13.

of transverse reinforcement with a diameter of $10 \mathrm{~mm}$ is $300 \mathrm{MPa}$. Assume that the bridge is located in the site of category III and second design seismic group according to the Chinese seismic design code (GB 50011-2010) [31].

The capacity spectrum method is adopted for analyzing the seismic response of the abovementioned RC bridge structure with a single column, and the pushover curve (i.e., the capacity curve) and inelastic demand spectrum curve of the bridge should be established reasonably. Considering that the bridge with well-confined RC piers will exhibit obvious flexural response under seismic loading, the lateral load-displacement curve (i.e., pushover curve) of the bridge pier can be obtained by the sectional analysis technology, as illustrated in Figure 16. In the analysis, the stress-strain models for cover concrete and confined concrete developed by Mander et al. [32] are adopted, and the stress-strain model for steel reinforcing bars developed by Esmaeily-Gh and Xiao [33] is adopted. For the pushover curve of the bridge pier in Figure 16, the lateral displacement and yield force are $d_{\mathrm{y}}=34.67 \mathrm{~mm}$ and $F_{\mathrm{y}}=323.44 \mathrm{kN}$, respectively, and yield stiffness is $k_{\mathrm{y}}=F_{\mathrm{y}} / d_{\mathrm{y}}=9329.61 \mathrm{kN} / \mathrm{m}$. Assuming that the target displacement and corresponding lateral load of the bridge is $d_{\mathrm{p}}$ $\left(d_{\mathrm{p}}>d_{\mathrm{y}}\right)$ and $F_{\mathrm{p}}$, the ductility factor $\mu$, secant stiffness $k_{\mathrm{sec}}$, and equivalent period $T_{\mathrm{e}}$ of the bridge can be determined, that is, $\mu=d_{\mathrm{p}} / d_{\mathrm{y}}, k_{\mathrm{sec}}=F_{\mathrm{p}} / d_{\mathrm{p}}$, and $T_{\mathrm{e}}=2 \pi \sqrt{m / k_{\mathrm{sec}}}$.

The inelastic demand spectrum of the bridge is obtained based on the elastic demand spectrum with higher EVD ratio in this study according to ATC-40 [10]. The EVD ratio $\zeta_{\text {eff }}$ can be predicted by (18), and the elastic acceleration demand spectrum suggested by the Chinese seismic design code (GB 50011-2010) [31] is adopted and expressed as follows: 


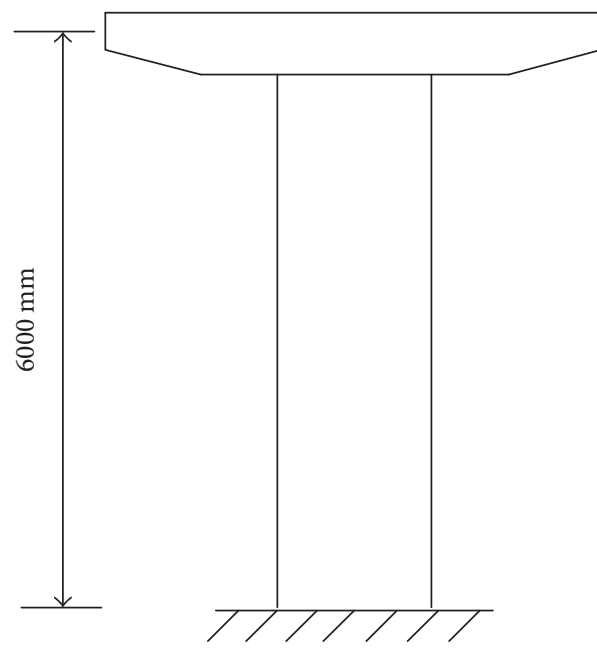

(a)

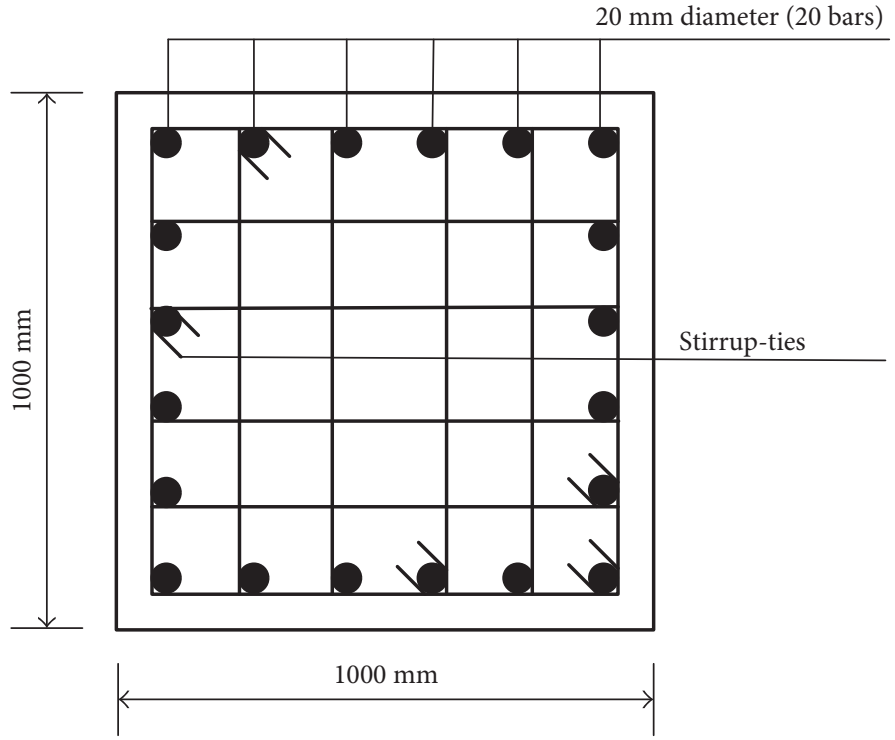

(b)

FIGURE 15: Single pier of the bridge. (a) Single pier. (b) Cross section and reinforcement details.

$$
\begin{aligned}
S_{a}(T) & = \begin{cases}\alpha_{\max } g\left[0.45+10 T\left(\eta_{2}-0.45\right)\right], & 0 \leq T \leq 0.1 \\
\alpha_{\max } \eta_{2} g, & 0.1 \leq T \leq T_{\mathrm{g}} \\
\left(\frac{T_{\mathrm{g}}}{T}\right)^{\gamma} \alpha_{\max } \eta_{2} g, & T_{\mathrm{g}} \leq T \leq 5 T_{\mathrm{g}} \\
\alpha_{\max } g\left[0.2^{\gamma} \eta_{2}-\eta_{1}\left(T-5 T_{\mathrm{g}}\right)\right], & 5 T_{\mathrm{g}} \leq T \leq 6.0,\end{cases} \\
\gamma & =0.9+\frac{0.05-\zeta_{\mathrm{eff}}}{0.3+6 \zeta_{\mathrm{eff}}}, \\
\eta_{1} & =0.02+\frac{0.05-\zeta_{\mathrm{eff}}}{4+32 \zeta_{\mathrm{eff}}} \geq 0,
\end{aligned}
$$

where $g$ is the acceleration of gravity; $\alpha_{\max }$ is the seismic influence factor and adopts 0.4 for the ground peak acceleration of $0.4 \mathrm{~g} ; T$ is the structural period and equal to the equivalent period $T_{\mathrm{e}}$ in the analysis; $T_{\mathrm{g}}$ is the design characteristic period of ground motion and equals to 0.55 for site category III and the second seismic design group; and $\gamma$, $\eta_{1}$, and $\eta_{2}$ are parameters associated with the damping of the structures.

According to (19), the inelastic displacement demand spectrum can be converted using the following expression:

$$
S_{\mathrm{d}}(T)=S_{\mathrm{a}}(T)\left(\frac{T}{2 \pi}\right)^{2}
$$

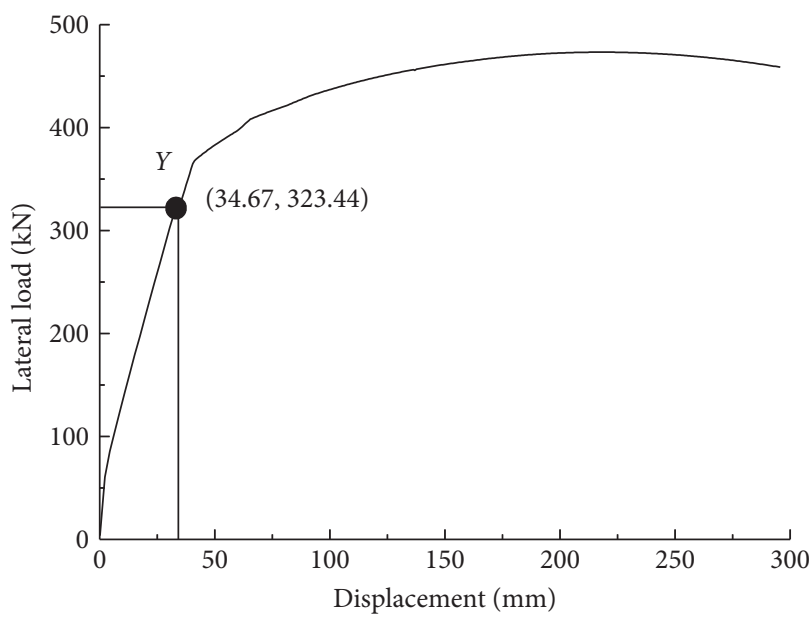

FIgURE 16: Lateral load-displacement curve of the bridge.

For a given seismic level, if the assumed target displacement $d_{\mathrm{p}}$ is (approximately) equal to the spectrum displacement $S_{\mathrm{d}}\left(T_{\mathrm{e}}\right)$, then $d_{\mathrm{p}}$ is the required seismic displacement response of the bridge structure, and the corresponding point on the pushover curve is the required seismic performance point. Figure 17 shows the performance points of the bridge structure determined through the iteration method using (18) in the acceleration-displacement response spectra (ADRS) domain. For the purpose of comparison, pushover analysis are also made using the EVD equations proposed by Rosenblueth [9] and Kowalsky [12], respectively, both of which are incorporated in the design code such as the ATC-40 [10] and California Building Code (2013). As shown in Figure 17, the target displacement in the top of the pier is $88.90 \mathrm{~mm}$ and the equivalent damping ratio is $22.36 \%$ for the proposed model, and $81.05 \mathrm{~mm}$ and $26.64 \%$ for the Rosenblueth's model, while they are 


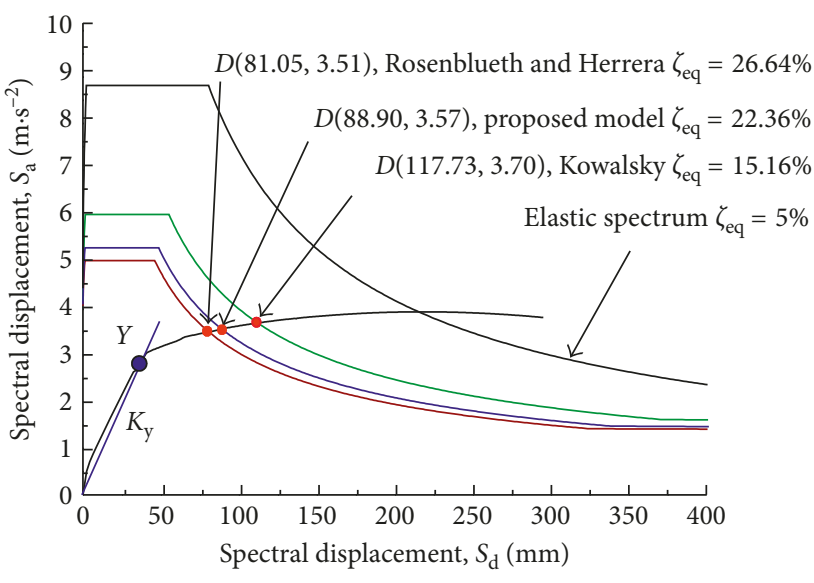

FIGURe 17: Performance points and target displacements in ADRS domain.

$117.73 \mathrm{~mm}$ and $15.16 \%$ for Kowalsky's model. The predicted target displacement using the proposed model is between those using Rosenblueth's model and Kowalsky's model. This suggests that the proposed model in this study may be more general and rational in estimating the equivalent damping ratios of the flexure critical RC structures and members. The reason can be explained that the equivalent damping ratio values may be overestimated or underestimated by using the two abovementioned models in previous researches. Undoubtedly, the quantification of the energy dissipation of structures is the key of the equivalent linearization method and direct displacementbased seismic design method, and the proposed model of the equivalent damping ratio (i.e., (18)) is a reasonably available model just for RC structures and members controlled by flexure response under seismic excitation. If the seismic damage of $\mathrm{RC}$ structures and members are controlled by the flexure-shear mode, the energy dissipation capacity should be predicted by the appropriate model considering shear effects such as the model reported by Zhang et al. [26].

\section{Conclusion}

A new EVD ratio model for describing the complete hysteretic loops of flexure critical RC columns is derived and simplified based on theoretical derivation and analysis of experimental results of RC columns from the PEER database. For the proposed model, the displacement ductility factor and postyielding stiffness ratio of columns as two key parameters are considered, and the predicted results of energy dissipation capacity of columns agree well with those derived from the experimental data. A case study of pushover analysis for a RC bridge with flexure critical pier illustrates that the proposed EVD ratio model is more general and rational in predicting the energy dissipation capacity of RC columns compared with the other models.

\section{Appendix}

Derivation of (16a)-(16c).
For the indeterminate integration with integrands $1 / a+b x+c x^{2}$ and $x / a+b x+c x^{2}$, the mathematic handbook [34] gives

$$
\begin{aligned}
& \int \frac{d x}{a+b x+c x^{2}}=\frac{2}{\sqrt{q}} \arctan \frac{2 c x+b}{\sqrt{q}}+C \quad(q>0), \\
& \int \frac{d x}{a+b x+c x^{2}}=\frac{1}{\sqrt{-q}} \ln \left|\frac{2 c x+b-\sqrt{-q}}{2 c x+b+\sqrt{-q}}\right| \quad(q<0), \\
& \int \frac{x d x}{a+b x+c x^{2}}=\frac{1}{2 c} \ln \left|a+b x+c x^{2}\right|-\frac{b}{2 c} \int \frac{d x}{a+b x+c x^{2}} .
\end{aligned}
$$

where $q=4 a c-b^{2}$ and $C$ is a constant. For determinate integration with the same integrand, $C=0$.

If $q=0$, then $1 / a+b x+c x^{2}$ becomes

$$
\begin{aligned}
\frac{1}{a+b x+c x^{2}} & =\frac{1}{c(x+(b / 2 c))^{2}+\left(4 a c-b^{2} / 4 c\right)} \\
& =\frac{1}{c(x+(b / 2 c))^{2}} .
\end{aligned}
$$

Thus,

$$
\begin{aligned}
\int \frac{d x}{a+b x+c x^{2}} & =\int \frac{d x}{c(x+(b / 2 c))^{2}} \\
& =-\frac{1}{c(x+(b / 2 c))}+C, \\
\int \frac{x d x}{a+b x+c x^{2}} & =\int \frac{x d x}{c(x+(b / 2 c))^{2}} \\
& =\frac{1}{c}\left[\ln \left(x+\frac{b}{2 c}\right)+\frac{(b / 2 c)}{x+(b / 2 c)}\right]+C .
\end{aligned}
$$

Equation (15) can be rewritten as

$$
\begin{aligned}
E_{\mathrm{hys}}= & 2 y_{3} \int_{-x_{1}}^{x_{1}} \frac{1}{1+\alpha\left(x / x_{1}\right)-(1-\alpha(\mu / \gamma))\left(x / x_{1}\right)^{2}} d x \\
& +2 \frac{y_{3}}{x_{2}} \int_{-x_{1}}^{x_{1}} \frac{x}{1+\alpha\left(x / x_{1}\right)-(1-\alpha(\mu / \gamma))\left(x / x_{1}\right)^{2}} d x .
\end{aligned}
$$

According to the integrants of (A.1) and (A.2), the parameters $a, b$, and $c$ in (A.7) can be expressed as follows:

$$
\begin{aligned}
& a=1, \\
& b=\alpha \frac{1}{x_{1}} \\
& c=-\frac{1}{x_{1}^{2}}\left(1-\alpha \frac{\mu}{\lambda}\right) .
\end{aligned}
$$

Let $\beta=\alpha^{2}+4-(4 \alpha \mu / \lambda)$, then $q=-\left(\beta / x_{1}^{2}\right)$, and three cases are discussed for solving the integration of (A.7) as follows:

Case I: $\beta<0$. 
In this case, $q>0$ and (A.1) is valid. Using (A.3) and (A.1), (A.7) becomes

$$
\begin{aligned}
& E_{\text {hys }}=2 y_{3} \int_{-x_{1}}^{x_{1}} \frac{1}{1+\alpha\left(x / x_{1}\right)-(1-\alpha(\mu / \lambda))\left(x / x_{1}\right)^{2}} d x \\
& +2 \frac{y_{3}}{x_{2}}\left[\frac{-x_{1}^{2}}{2(1-\alpha(\mu / \lambda))} \ln \left|1+\alpha \frac{x}{x_{1}}-\left(1-\alpha \frac{\mu}{\lambda}\right)\left(\frac{x}{x_{1}}\right)^{2}\right|\right. \\
& +\frac{\alpha x_{1}}{2(1-\alpha(\mu / \lambda))} \\
& \left.\cdot \int_{-x_{1}}^{x_{1}} \frac{1}{1+\alpha\left(x / x_{1}\right)-(1-\alpha(\mu / \lambda))\left(x / x_{1}\right)^{2}} d x\right] \\
& =2\left[y_{3}+\frac{y_{3}}{x_{2}} \times \frac{\alpha x_{1}}{2(1-\alpha(\mu / \lambda))}\right] \\
& \int_{-x_{1}}^{x_{1}} \frac{1}{1+\alpha\left(x / x_{1}\right)-(1-\alpha(\mu / \lambda))\left(x / x_{1}\right)^{2}} d x \text {, } \\
& +2 \frac{y_{3}}{x_{2}}\left[\frac{-x_{1}^{2}}{2(1-\alpha(\mu / \lambda))} \ln \left|1+\alpha \frac{x}{x_{1}}-\left(1-\alpha \frac{\mu}{\lambda}\right)\left(\frac{x}{x_{1}}\right)^{2}\right|\right] \text {, } \\
& =\frac{4 x_{1} y_{3}[1+(\alpha(\mu / \lambda) / 2(1-\alpha(\mu / \lambda)))]}{\sqrt{|\beta|}} \\
& \cdot\left[\arctan \frac{(-2(1-\alpha(\mu / \lambda))+\alpha)}{\sqrt{|\beta|}}\right. \\
& \left.-\arctan \frac{(2(1-\alpha(\mu / \lambda))+\alpha)}{\sqrt{|\beta|}}\right] \\
& +2 \frac{y_{3}}{x_{2}} \frac{-x_{1}^{2}}{2(1-\alpha(\mu / \lambda))}\left[\ln \left|1+\alpha-\left(1-\alpha\left(\frac{\mu}{\lambda}\right)\right)\right|\right. \\
& \left.-\ln \left|1-\alpha-\left(1-\alpha\left(\frac{\mu}{\lambda}\right)\right)\right|\right] \text {, } \\
& =\frac{4 x_{1} y_{3}[1+(\alpha(\mu / \lambda) / 2(1-\alpha(\mu / \lambda)))]}{\sqrt{|\beta|}} \\
& \cdot\left[\arctan \frac{(-2(1-\alpha(\mu / \lambda))+\alpha)}{\sqrt{|\beta|}}\right. \\
& \left.-\arctan \frac{(2(1-\alpha(\mu / \lambda))+\alpha)}{\sqrt{|\beta|}}\right] \\
& +2 \frac{y_{3}}{x_{2}} \frac{-x_{1}^{2}}{2(1-\alpha(\mu / \lambda))} \ln \left|\frac{1+\alpha-(1-\alpha(\mu / \lambda))}{1-\alpha-(1-\alpha(\mu / \lambda))}\right| \text {, } \\
& =\frac{4 x_{1} y_{3}[1+(\alpha(\mu / \lambda) / 2(1-\alpha(\mu / \lambda)))]}{\sqrt{|\beta|}}
\end{aligned}
$$

$$
\begin{aligned}
& \cdot\left[\arctan \frac{(-2(1-\alpha(\mu / \lambda))+\alpha)}{\sqrt{|\beta|}}\right. \\
& \left.-\arctan \frac{(2(1-\alpha(\mu / \lambda))+\alpha)}{\sqrt{|\beta|}}\right] \\
& -x_{1} y_{3} \frac{(\mu / \lambda)}{(1-\alpha(\mu / \lambda))} \ln \mid \frac{\mu+\lambda \mid}{\mu-\lambda \mid}, \\
& =\frac{4 x_{1} y_{1} \alpha[1+(\alpha(\mu / \lambda) / 2(1-\alpha(\mu / \lambda)))]}{\sqrt{|\beta|}} \\
& \cdot\left[\arctan \frac{(-2(1-\alpha(\mu / \lambda))+\alpha)}{\sqrt{|\beta|}}\right. \\
& \left.-\arctan \frac{(2(1-\alpha(\mu / \lambda))+\alpha)}{\sqrt{|\beta|}}\right] \\
& -x_{1} y_{1} \alpha \frac{(\mu / \lambda)}{(1-\alpha(\mu / \lambda))} \ln \frac{\mu+\lambda}{\mu-\lambda} .
\end{aligned}
$$

Case III: $\beta>0$.

In this case, (A.2) is valid. Following the same procedure of derivation of (A.9), (A.7) becomes

$$
\begin{aligned}
E_{\mathrm{hys}}= & \frac{2 x_{1} y_{3}[1+(\mu / \lambda)(\alpha / 2(1-\alpha(\mu / \lambda)))]}{\sqrt{\beta}} \\
& \cdot \ln \left|\frac{\alpha^{2}-[2(1-\alpha(\mu / \lambda))+\sqrt{\beta}]^{2}}{\alpha^{2}-[2(1-\alpha(\mu / \lambda))-\sqrt{\beta}]^{2}}\right| \\
& +2 \frac{y_{3}}{x_{2}}\left[\frac{-x_{1}^{2}}{2(1-\alpha(\mu / \lambda))} \ln \left|\frac{1+\alpha-(1-\alpha(\mu / \lambda))}{1-\alpha-(1-\alpha(\mu / \lambda))}\right|\right] \\
= & \frac{2 x_{1} y_{1} \alpha[1+(\alpha(\mu / \lambda) / 2(1-\alpha(\mu / \lambda)))]}{\sqrt{\beta}} \\
& \cdot \ln \left|\frac{\alpha^{2}-[2(1-\alpha(\mu / \lambda))+\sqrt{\beta}]^{2}}{\alpha^{2}-[2(1-\alpha(\mu / \lambda))-\sqrt{\beta}]^{2}}\right| \\
& -\frac{2 \alpha(\mu / \lambda) x_{1} y_{1}}{2(1-\alpha(\mu / \lambda))} \ln \frac{\mu+\lambda}{\mu-\lambda} .
\end{aligned}
$$

Case II: $\beta=0$.

In this case, (A.5) and (A.6) are valid. Equation (A.7) becomes

$$
E_{\mathrm{hys}}=\frac{-2 y_{3} x_{1}^{2}}{1-\alpha(\mu / \lambda)} \int_{-x_{1}}^{x_{1}} \frac{d x}{\left[x-\left(\alpha x_{1} / 2(1-\alpha(\mu / \lambda))\right)\right]^{2}}
$$




$$
\begin{aligned}
& \quad y_{\mathrm{DEFA}} \text { : Ordinate at the upper branch DEFA of the } \\
& -\frac{2 y_{3} x_{1}^{2}}{x_{2}(1-\alpha(\mu / \lambda))} \int_{-x_{1}}^{x_{1}} \quad x d x \quad \text { hysteretic loop in Figure } 6 \\
& \begin{array}{lll}
-\overline{x_{2}(1-\alpha(\mu / \lambda))} \int_{-x_{1}} \overline{\left[x-\left(\alpha x_{1} / 2(1-\alpha(\mu / \lambda))\right)\right]^{2}}, & \lambda: & \begin{array}{l}
\text { Normalized residual lateral displacement } \\
\text { Ductility factor }
\end{array} \\
=\frac{-2 y_{3} x_{1}^{2}}{1-\alpha(\mu / \lambda)} \times \frac{2 \alpha^{2}}{x_{1}\left(\alpha^{2}-4\right)}-\frac{2 y_{3} x_{1}^{2}}{x_{2}(1-\alpha(\mu / \lambda))} & \begin{array}{l}
\alpha_{\max }: \\
\text { Seismic influence factor in the Chinese seismic } \\
\text { code }
\end{array}
\end{array} \\
& \left\{\ln \frac{2+\alpha}{2-\alpha}-\left[\frac{\alpha}{2(1-\alpha(\mu / \lambda))-\alpha}+\frac{\alpha}{2(1-\alpha(\mu / \lambda))+\alpha}\right]\right\}, \underset{\zeta_{\text {eff }}}{ } \text { : } \\
& =\frac{8 \alpha x_{1} y_{1}}{4(1-\alpha(\mu / \lambda))^{2}-\alpha^{2}}\left(2-\alpha \frac{\mu}{\lambda}\right) \\
& -\frac{2 \alpha x_{1} y_{1}}{1-\alpha(\mu / \lambda)}\left(\frac{\mu}{\lambda}\right) \ln \frac{2+\alpha}{2-\alpha} .
\end{aligned}
$$

\section{Notation} expression

$a, b, c, d: \quad$ Constant

$E_{\mathrm{el}}: \quad \quad$ Elastic displacement energy

$E_{\text {hys }}$ : $\quad$ Energy dissipation in a complete hysteretic cycle

$F: \quad$ Lateral force

$F_{1}$ : $\quad$ Force corresponding to the maximum displacement of a complete hysteretic loop

$F_{3}$ : $\quad$ Force to restore the element to its initial position

$F_{\text {max }}: \quad$ Maximum force in the force-displacement curve of the element

$F_{\mathrm{p}}$ : $\quad$ Force corresponding to target displacement in the force-displacement curve

$F_{\mathrm{y}}$ : $\quad$ Yield force

g: $\quad$ Acceleration of gravity

$H$ : $\quad$ Height of the bridge structure

$k_{\text {sec }}: \quad$ Secant stiffness

$k_{\mathrm{y}}: \quad$ Yield stiffness

$m$ : Concentrated mass of the bridge

$r$ : $\quad$ Ratio of second stiffness to yield stiffness of the structure

$S_{\mathrm{a}}: \quad$ Spectrum acceleration

$S_{\mathrm{d}}: \quad$ Spectrum displacement

T: $\quad$ Period of the structure

$T_{\mathrm{e}}: \quad$ Equivalent period

$T_{\mathrm{g}}$ : $\quad$ Characteristic period defined in the Chinese seismic code

$x: \quad$ Ratio of displacement to yield displacement

$x_{1}$ : $\quad$ Ratio of maximum displacement to yield displacement

$x_{2}$ : $\quad$ Ratio of residual displacement to yield displacement

$y: \quad$ Ratio of force to yield force

$y_{1}$ : $\quad$ Ratio of force corresponding to maximum displacement to yield force

$y_{3}$ : $\quad$ Ratio of force corresponding to zero displacement to yield force

$\alpha: \quad$ Ratio of $y_{3}$ to $y_{1}$

\section{Conflicts of Interest}

The authors declare that they have no conflicts of interest.

\section{Acknowledgments}

The work in this paper was financed by the Natural Science Foundation of China (nos. 51678104, 51478077, and 51508154), the Natural Science Foundation of Jiangsu Province (BK20150803), the China Postdoctoral Science Foundation (2015M581711), and the Priority Academic Program Development of Jiangsu Higher Education Institutions. The authors wish to express their gratitude for these financial support.

\section{References}

[1] Q. Zhang, N. Wang, and J. Gong, "State of the art of seismic performance including shear effects and failure modes of reinforced concrete columns," Journal of Building Structures, vol. 38, no. 8, pp. 1-13, 2017.

[2] M. J. N. Priestley, G. M. Calvi, and M. J. Kowalsky, Direct Displacement Based Design of Structures, IUSS Press, Pavia, Italy, 2007.

[3] E. Khan, T. J. Sullivan, and M. J. Kowalsky, "Direct arch bridges," ASCE Journal of Bridge Engineering, vol. 19, no. 1, pp. 44-58, 2014. equivalent linearization of bridges supported on hysteretic isolators," Engineering Structures, vol. 35, pp. 99-106, 2012.

[5] T. Liu, T. Zordan, B. Briseghella, and Q. Zhang, "Evaluation of equivalent linearization analysis methods for seismically isolated buildings characterized by SDOF systems," Engineering Structures, vol. 59, pp. 619-634, 2014.

[6] E. Khan, M. J. Kowalsky, and J. M. Nau, "Equivalent viscous damping model for short-period reinforced concrete bridges," Journal of Bridge Engineering, vol. 21, no. 2, article 04015047, 2016. displacement-based seismic design of reinforced concrete

[4] M. Jara, J. M. Jara, and J. R. Casas, "Improved procedure for 
[7] R. Zaharia and F. Taucer, "Equivalent period and damping for EC8 spectral response of SDOF ring-spring hysteretic models," Institute for the Protection and Security of the Citizen, Joint Research Centre, European Commission, Luxembourg, 2008.

[8] L. S. Jacobsen, "Steady forced vibration as influenced by damping," Transactions ASME, vol. 52, no. 1, pp. 169-181, 1930.

[9] E. Rosenblueth and I. Herrera, "On a kind of hysteretic damping," Journal of Engineering Mechanics Division, vol. 90, no. 1, pp. 37-48, 1964.

[10] Applied Technology Council, "Seismic evaluation and retrofit of concrete buildings," Report ATC-40, Seismic Safety Commission, Redwood City, CA, USA, 1996.

[11] Federal Emergency Management Agency, "Improvement of nonlinear static seismic analysis procedures," FEMA 440, Federal Emergency Management Agency, Washington, DC, USA, 2005.

[12] M. J. Kowalsky, M. J. N. Priestley, and G. A. Macrae, "Displacement-based design of RC bridge columns in seismic regions," Earthquake Engineering and Structural Dynamics, vol. 24, no. 21, pp. 1623-1643, 1995.

[13] T. Takeda, M. A. Sozen, and N. N. Neilsen, "Reinforced concrete response to simulated earthquakes," Journal of the Structural Division, vol. 96, no. 12, pp. 2557-2573, 1970.

[14] G. Pekcan, J. B. Mander, and S. S. Chen, "Fundamental considerations for the design of non-linear viscous dampers," Earthquake Engineering and Structural Dynamics, vol. 28, no. 11, pp. 1405-1425, 1999.

[15] P. Gülkan and M. Sozen, "Inelastic response of reinforced concrete structures to earthquake motions," ACI Structural Journal, vol. 71, no. 12, pp. 604-610, 1974.

[16] W. D. Iwan, "Estimating inelastic response spectra from elastic spectra," Earthquake Engineering and Structural Dynamics, vol. 8, no. 4, pp. 375-388, 1980.

[17] W. P. Kwan and S. L. Billington, "Influence of hysteretic behavior on equivalent period and damping of structural systems," ASCE Journal of Structural Engineering, vol. 129, no. 5, pp. 576-585, 2003.

[18] H. Rodrigues, H. Varum, A. Arêde, and A. Costa, "A comparative analysis of energy dissipation and equivalent viscous damping of RC columns subjected to uniaxial and biaxial loading," Engineering Structures, vol. 35, pp. 149-164, 2012.

[19] T. Liu and $Q$. Zhang, " $A_{P} / V_{P}$ specific equivalent viscous damping model for base-isolated buildings characterized by SDOF systems," Engineering Structures, vol. 111, pp. 36-47, 2016.

[20] C. Chisari, C. Bedon, and C. Amadio, "Dynamic and static identification of base-isolated bridges using Genetic Algorithms," Engineering Structures, vol. 102, pp. 80-92, 2015.

[21] C. Bedon and A. Morassi, "Dynamic testing and parameter identification of a base-isolated bridge," Engineering Structures, vol. 60, pp. 85-99, 2014.

[22] E. Miranda and J. Ruiz-García, "Evaluation of approximate methods to estimate maximum inelastic displacement demands," Earthquake Engineering and Structural Dynamics, vol. 31, no. 3, pp. 539-560, 2002.

[23] C. A. Blandon and M. J. N. Priestley, "Equivalent viscous damping equations for direct displacement based design," Journal of Earthquake Engineering, vol. 9, no. 2, pp. 257-278, 2005.

[24] H. M. Dwairi, M. J. Kowalsky, and J. M. Nau, "Equivalent damping in support of direct displacement-based design," ASCE Journal of Structural Engineering, vol. 11, no. 4, pp. 512-530, 2007.
[25] PEER Structural Performance Database, Pacific Earthquake Engineering Research Center, University of California, Berkeley, CA, USA, 2004, http://www.ce.washington.edu/ peera1/.

[26] Y. Zhang, J. Gong, Q. Zhang, and S. Han, "Equivalent damping ratio model of flexure-shear critical RC columns," Engineering Structures, vol. 130, pp. 52-66, 2017.

[27] Committee European Normalization, "Eurocode 8: design of structures for earthquake resistance-part 1: general rules, seismic actions and rules for buildings," EN 1998-1: 2004, CEN, Brussels, Belgium, 2004.

[28] J. Hwang, "Evaluation of equivalent linear analysis methods of bridge isolation," ASCE Journal of Structural Engineering, vol. 122, no. 8, pp. 972-976, 1996.

[29] W. D. Iwan and A. Guyader, "A study of the accuracy of the capacity spectrum method in engineering analysis," in Proceedings of the 3rd US-Japan Workshop on Performance-Based Earthquake Engineering Methodology for Reinforced Concrete Building Structures, University of California, Berkeley, CA, USA, 2002.

[30] G. Cheng and L. Ye, "Estimation of input energy spectra of inelastic SDOF systems with equivalent linear method," Building Structure, vol. 37, no. 8, pp. 74-77, 2007.

[31] GB 50011-2010, Code for Seismic Design of Buildings, China Building Industry Press, Beijing, China, 2010.

[32] J. B. Mander, M. J. N. Priestley, and R. Park, "Theoretical stress-strain model for confined concrete," Journal of Structural Engineering, vol. 114, no. 8, pp. 1804-1826, 1988.

[33] A. Esmaeily-Gh and Y. Xiao, "Seismic behavior of bridge columns subjected to various loading patterns," PEER Report 2002/15, University of California, Berkeley, CA, USA, 2002.

[34] D. Zwillinger, CRC Standard Mathematical Tables and Formulae, CRC Press, Boca Raton, FL, USA, 2003. 


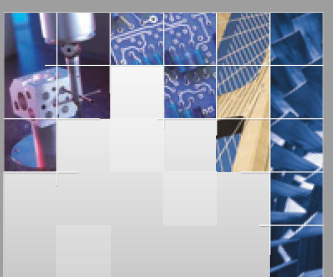

\section{Enfincering}
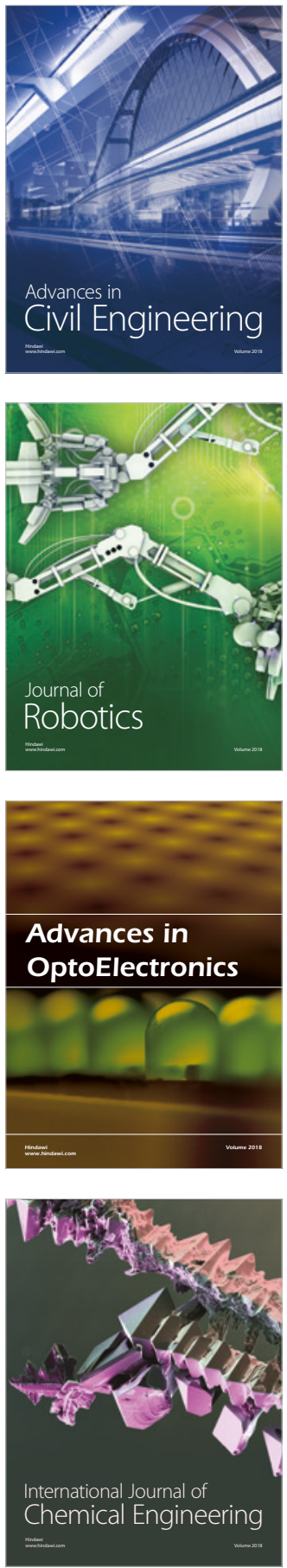

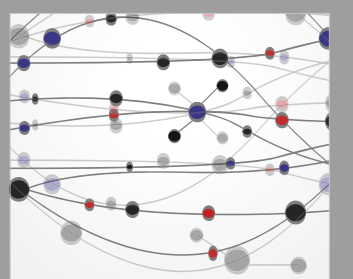

\section{Rotating \\ Machinery}

The Scientific World Journal

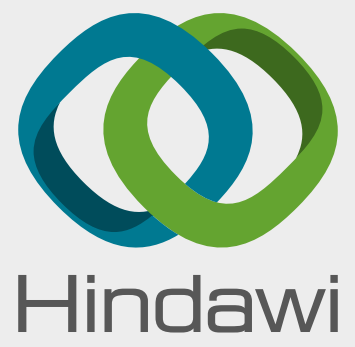

Submit your manuscripts at

www.hindawi.com
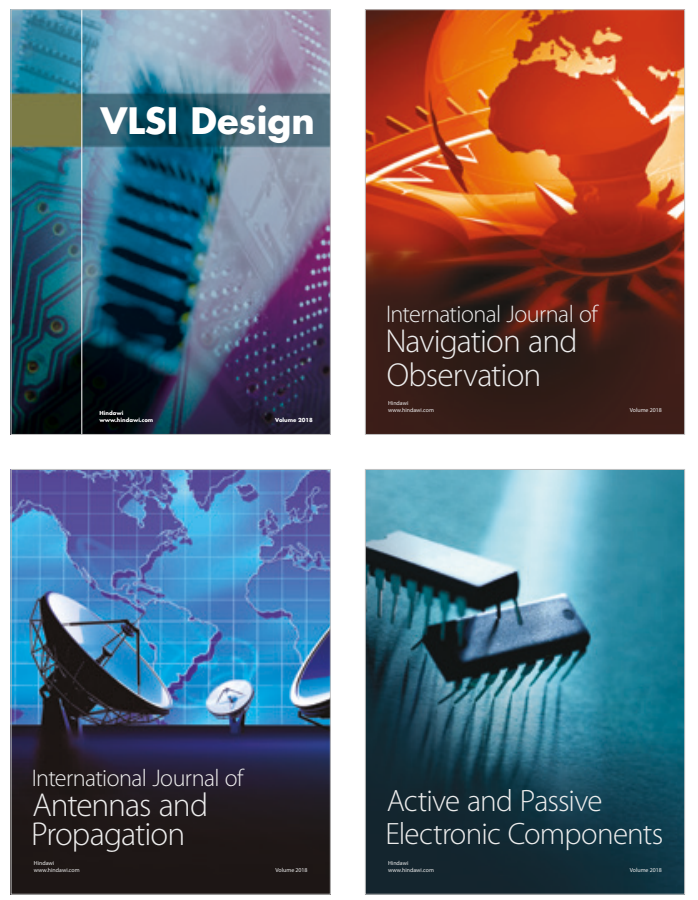
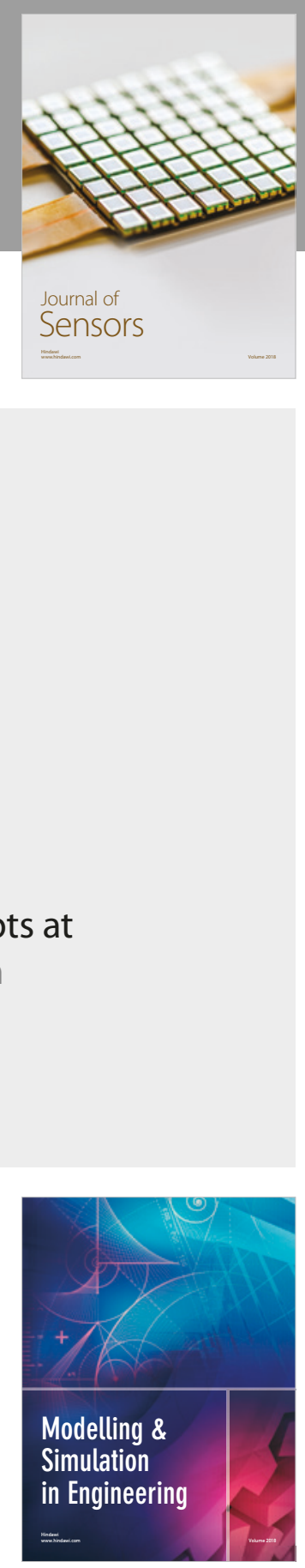

\section{Advances \\ Multimedia}
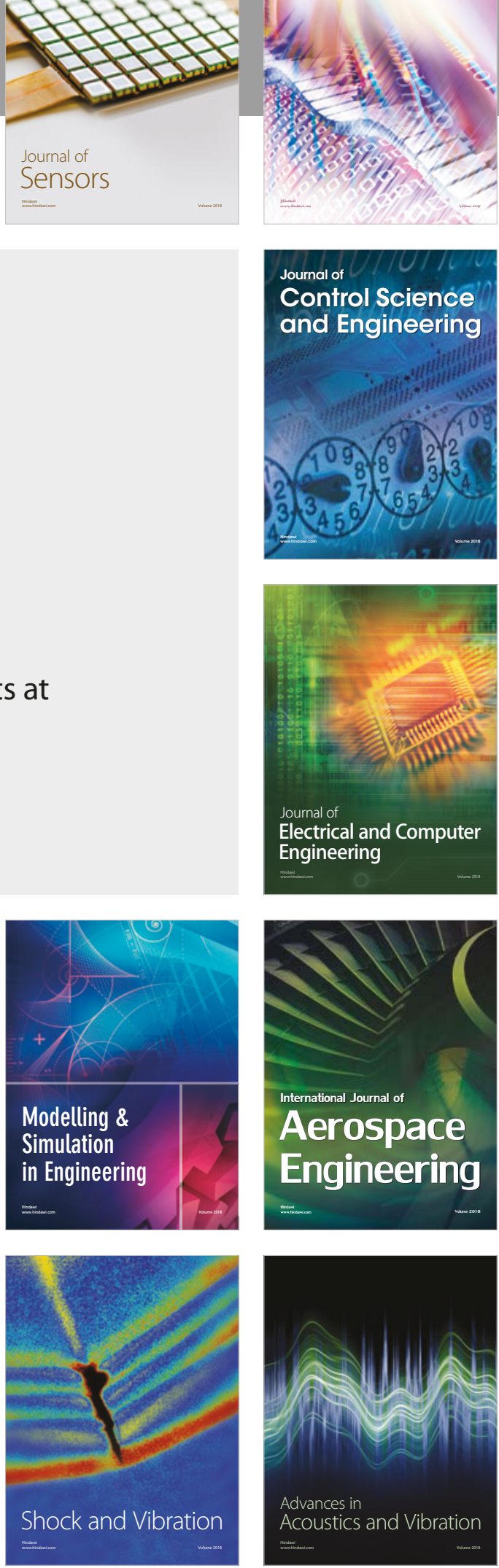